\title{
Graphene Oxide Induced Perturbation to Plasma Membrane and Cytoskeletal Meshwork Sensitize Cancer Cells to Chemotherapeutic Agents
}

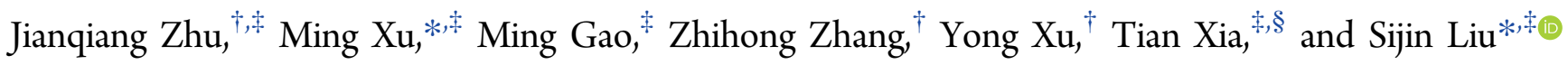 \\ ${ }^{\dagger}$ Department of Urology, The Second Hospital of Tianjin Medical University, Tianjin Institute of Urology, Tianjin 300211, China \\ ${ }^{\ddagger}$ State Key Laboratory of Environmental Chemistry and Ecotoxicology, Research Center for Eco-Environmental Sciences, Chinese \\ Academy of Sciences, Beijing 100085, China \\ ${ }^{\S}$ Division of NanoMedicine, Department of Medicine, University of California, Los Angeles, California 90095, United States
}

\section{Supporting Information}

\begin{abstract}
The outstanding physicochemical properties endow graphene materials (e.g., graphene oxide, GO) with beneficial potentials in diverse biomedical fields such as bioimaging, drug delivery, and biomolecular detection. GO recently emerged as a chemosensitizer; however, the detailed molecular basis underlying GO-conducted sensitization and corresponding biological effects are still elusive. Based on our recent findings that GO treatment at sublethal concentrations could impair the general cellular priming state, including disorders of plasma membrane and cytoskeleton construction, we aimed here to explore the mechanism of GO as a sensitizer to make cancer cells more susceptible to chemotherapeutic agents. We discovered that GO could not only compromise plasma membrane and cytoskeleton in J774A.1 macrophages and A549 lung cancer cells at sublethal concentrations without incurring significant cell death but also dampen a number of

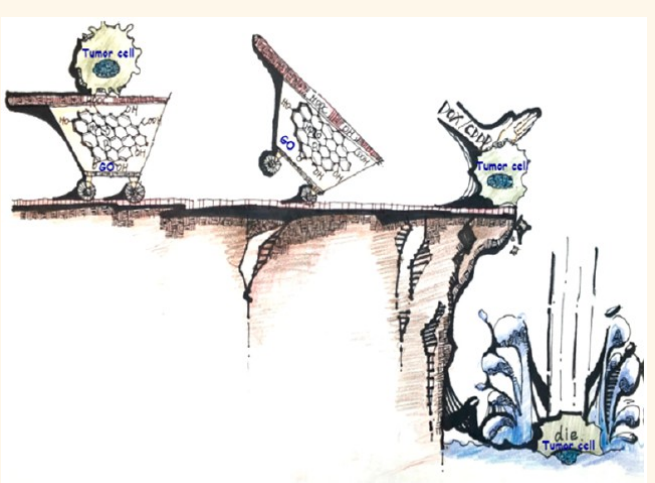
biological processes. Using the toxicogenomics approaches, we laid out the gene expression signature affected by GO and further defined those genes involved in membrane and cytoskeletal impairments responding to GO. The mechanistic investigation uncovered that the interactions of GO-integrin occurred on the plasma membrane and consequently activated the integrin-FAK-Rho-ROCK pathway and suppressed the expression of integrin, resulting in compromised cell membrane and cytoskeleton and a subsequent cellular priming state. By making use of this mechanism, the efficacy of chemotherapeutic agents (e.g., doxorubicin and cisplatin) could be enhanced by GO pretreatment in killing cancer cells. This study unveiled a feature of GO in cancer therapeutics: sensitizing cancer cells to chemotherapeutic agents by undermining the resistance capability of tumor cells against chemotherapeutic agents, at least partially, by compromising plasma membrane and cytoskeleton meshwork.
\end{abstract}

KEYWORDS: graphene oxide, cytoskeleton, plasma membrane, integrin, chemosensitizer, cancer therapy

$\mathrm{L}$

ung cancer is the leading cancer type worldwide, which accounts for the largest number of cancer deaths and substantial medical burden. ${ }^{1,2}$ Non-small cell lung cancer (NSCLC) makes up approximately $85 \%$ of all lung cancer cases, and the prognosis for NSCLC patients is poor, especially for patients with advanced tumors. ${ }^{3}$ Although substantial advances have been made for the treatment of NSCLC, such as through targeted and immunotherapy, the survival rate of these patients has not been significantly improved in the past $>30$ years. ${ }^{4}$ Therefore, continuing efforts are invested to look for alternative therapeutic approaches. Recently, complementary to conventional therapeutics, nano- material-based strategies have shown great potential in various cancer types, including lung cancer. ${ }^{5-7}$ Among nanomaterials, two-dimensional graphene oxide (GO) has high surface area and dispersibility that endows it with promising applications in the biomedical field, and numerous studies have documented that GO possesses desirable features in bioimaging, antimicrobial activities, drug delivery, and photothermal and photo-

Received: October 30, 2016

Accepted: February 16, 2017

Published: February 16, 2017 

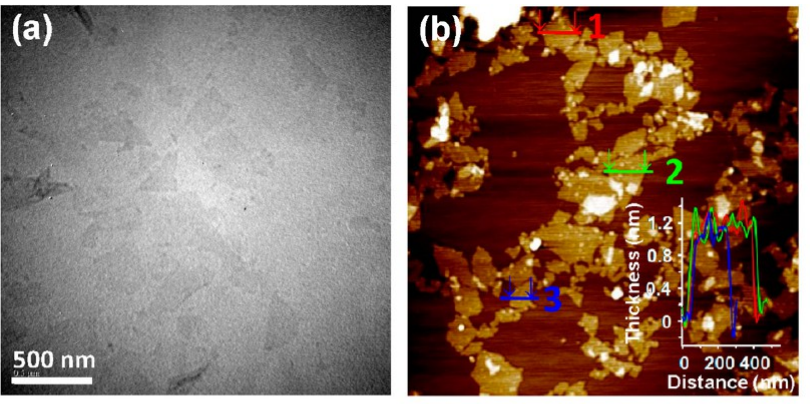

(c)

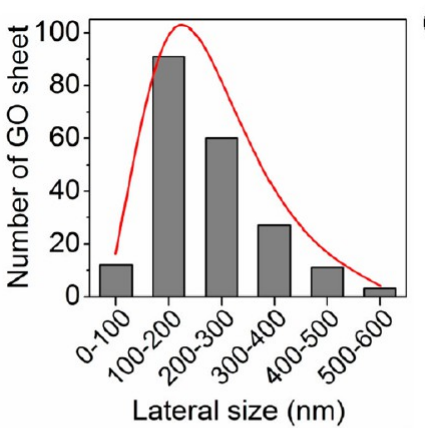

(d)

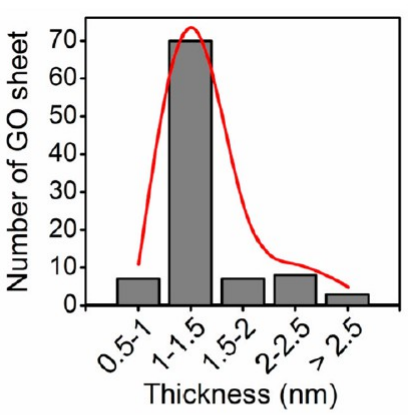

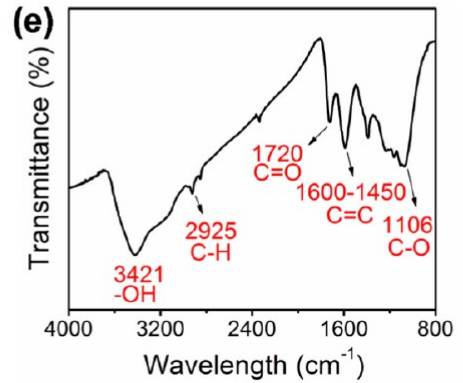
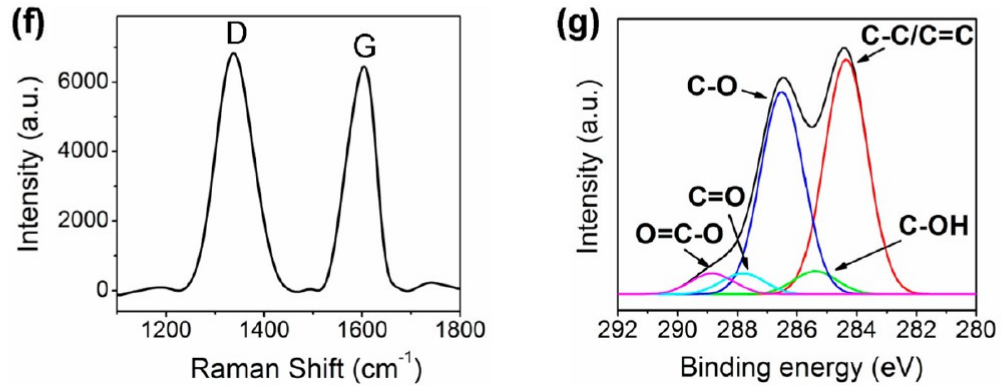

Figure 1. Characterization of GO materials. (a) Representative TEM image of GO sheets. (b) Representative AFM image showing GO sheets with height profiles. (c) Lateral size distribution of GO sheets based on the AFM data. The largest diameter of GO sheets was measured as the lateral size, and the histogram was developed by counting GO sheets $(n=200)$ with a Gaussian fit curve in histogram. (d) Thickness distribution of GO sheets based on the AFM data. The histogram was developed by counting GO sheets $(n=95)$ with a Gaussian fit curve in histogram. (e) FT-IR spectra of GO. The arrows indicate the characteristic peaks of differential chemical bonds. (f) Raman and (g) XPS spectra of the GO materials.

dynamic therapies. $^{8-10}$ Moreover, GO materials were also developed for additional purposes including regulating the tumor microenvironment and modulating tumor sensitivity to therapeutics; ${ }^{7,11-14}$ however, these studies were still in their infancy, and no detailed mechanisms have been revealed.

Chemosensitizers possess the ability to improve the cytotoxic action of anticancer chemotherapeutic agents, whereas they have little or low anticancer activity themselves. ${ }^{15}$ The mostly used chemosensitizers include agents to reverse multidrug resistance, drugs targeting hypoxia, delivery of genes and siRNA molecules, Chinese herbs, and other drugs. ${ }^{15-17}$ The main mechanisms include inhibition of drug pumps, reduction of glutathione metabolism-related enzymes, and targeting DNA topoisomerase II, DNA repair-related enzymes, and protein kinases. Meanwhile, new chemosensitizers are being developed to improve cancer therapeutics, especially for multidrug resistance and malignant cancers. ${ }^{16,17}$ Recent studies suggested that nanoparticle-mediated delivery of siRNA or miRNA molecules could greatly increase the efficacy of chemotherapeutic drugs against cancers, ${ }^{18}$ highlighting the application of nanomaterials in sensitizing cancer cells to chemotherapeutic agents.

GO-based cancer theranostics have recently been explored, and there are encouraging signs on these developments, including chemosensitization. ${ }^{7,19}$ However, the mechanisms of GO-mediated chemosensitization have not been studied in detail so far. Cellular priming state is a physiological state of a cell to determine the threshold and the responsiveness in reacting to exogenous and endogenous stimuli. ${ }^{20-22} \mathrm{We}$ previously showed the pro-inflammatory activation of macrophages induced by GO. ${ }^{23-26}$ We recently demonstrated that sublethal exposure of GO impaired the global cellular priming state, as evidenced by dysfunctions of the plasma membrane, cytoskeleton, ion channel/transporters, and energy metabolism, and these changes were partially accounted for by GO-induced DNA methylation variations. ${ }^{20}$ Our recent studies also showed an active association of GO with the plasma membrane of macrophages, leading to membrane damages and morphological impairments of macrophages. ${ }^{27}$ Impairments in the plasma membrane would break the cellular equilibrium for ions, proteins, and drugs, leading to cell injuries or even cell death. ${ }^{28}$ Herein, we aimed to explore whether GO-induced impairment of the cellular priming state could sensitize cancer cells to chemotherapeutic drugs, which could not be achieved by plasma membrane damage alone. Our combined data demonstrated that GO pretreatment at sublethal doses could significantly sensitize A549 lung cancer cells to chemotherapeutic agents, doxorubicin (DOX) and cis-diaminedichloroplatinum (cisplatin, CDDP). Our study thus would facilitate the development of GO-based cancer nanotherapeutics.

\section{RESULTS AND DISCUSSION}

GO Synthesis and Characterization. GO materials were synthesized as described in our recent report. ${ }^{27}$ Synthesized GO materials were thoroughly characterized by various techniques, and the characterization results are summarized in Figure 1. Representative transmission electron microscopy (TEM) images showed that the GO materials appeared in a sheet-like shape (Figure 1a). Atomic force microscopy (AFM) analysis revealed that the thickness of most GO sheets was approximately $1 \mathrm{~nm}$, indicating that the majority of GO sheets were monolayer (Figure $1 \mathrm{~b}, \mathrm{~d}$ ). The variability in their thickness in the AFM and TEM images came from the overlaid $(n \geq 2)$ and wrinkled GO sheets resulting from the drying processes during GO preparation, as previously demonstrated. ${ }^{29}$ The lateral size distribution of GO sheets was analyzed based on the 
(a)

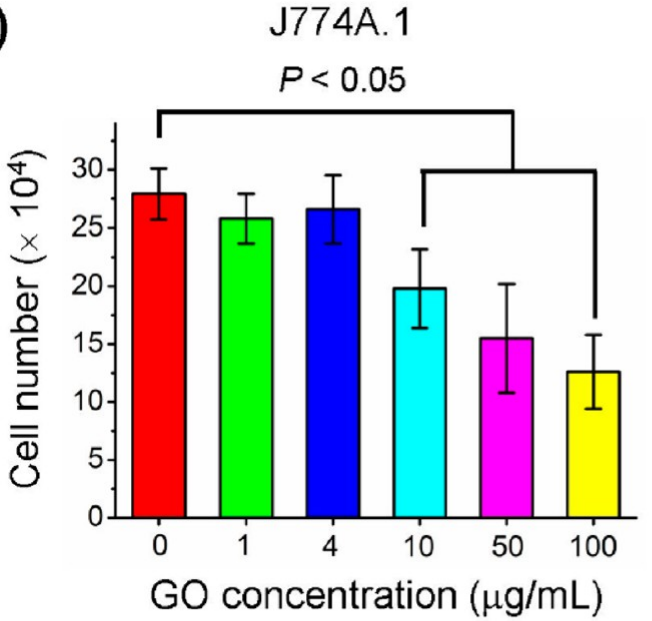

(b)

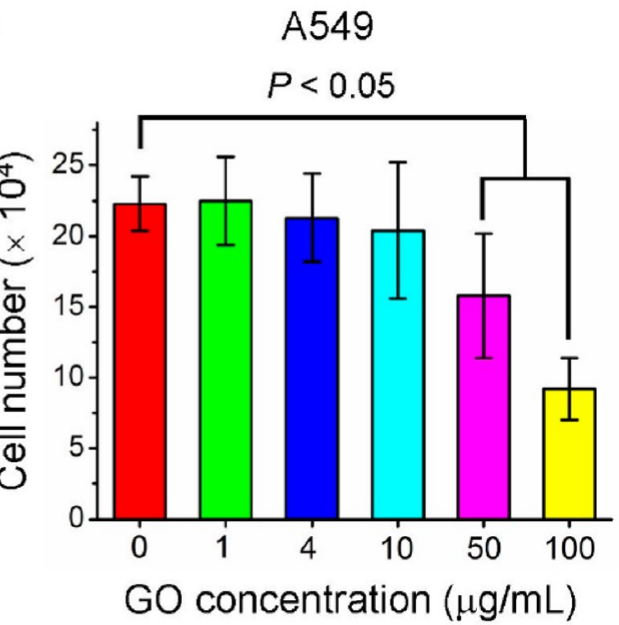

(c)
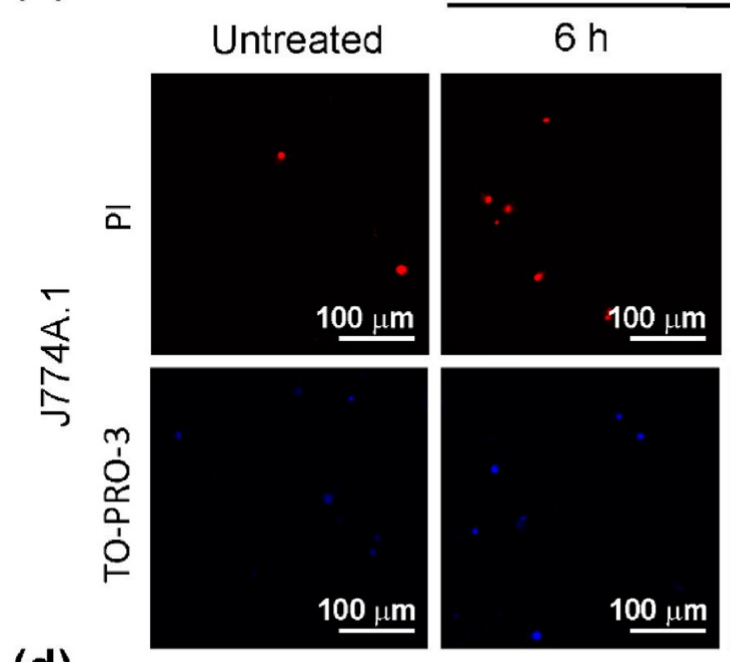

GO-treated

(d)

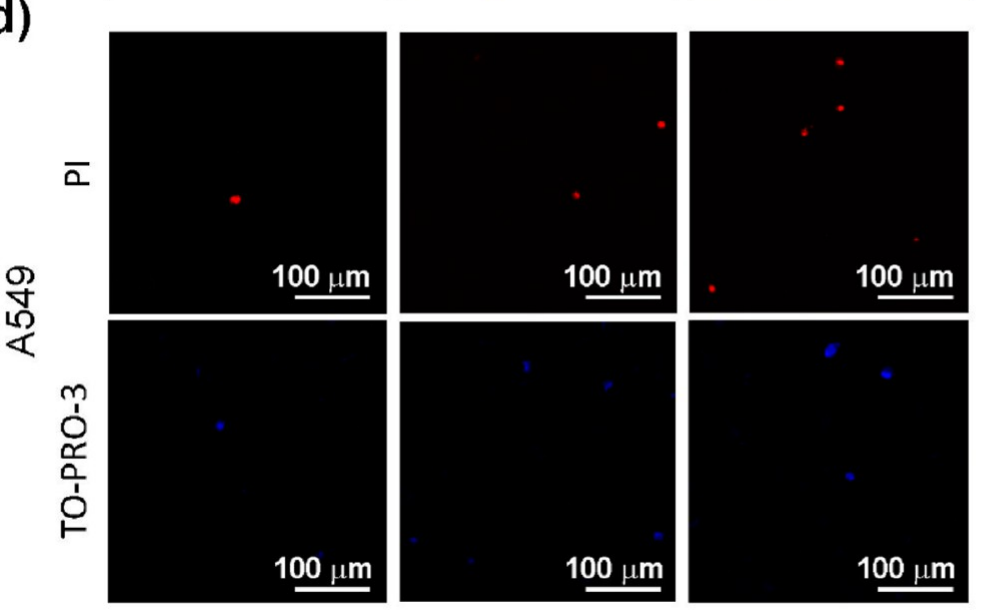

(e) J774A.1

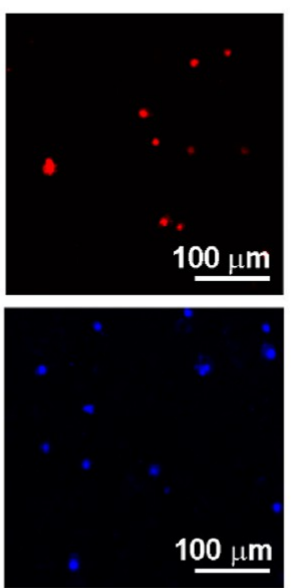

(f)

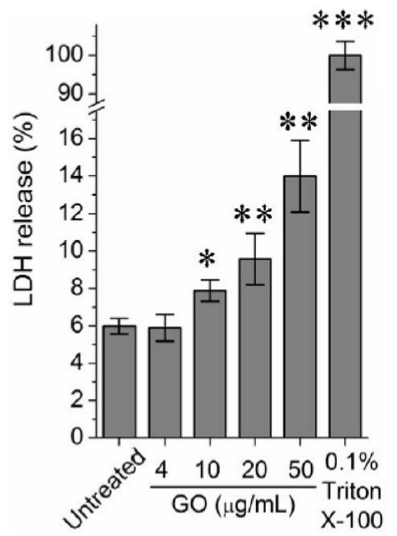

A549

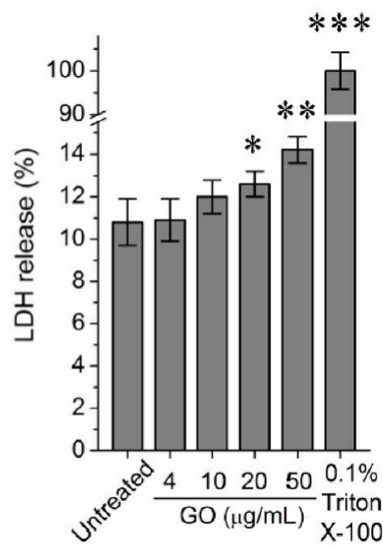

Figure 2. Cytotoxicity and membrane permeability determination upon GO. (a,b) Cytotoxicity of GO to (a) J774A.1 and (b) A549 cells at various concentrations for $24 \mathrm{~h}$ was determined by cell counting $(n=4)$. (c,d) Confocal microscopy images with PI staining (in red) and TOPRO-3 staining (in blue) reflecting membrane permeability after GO treatment for (c) J774A.1 cells at $4 \mu \mathrm{g} / \mathrm{mL}$ and (d) A549 cells at $10 \mu \mathrm{g} /$ $\mathrm{mL}$ for $24 \mathrm{~h}$. (e,f) Levels of LDH release into culture medium from (e) J774A.1 and (f) A549 cells upon GO treatment at different concentrations for $24 \mathrm{~h}(n=5)$. The cell membrane integrity (LDH release) was calculated relative to the positive control $(100 \%)$ of $0.1 \%$ Triton X-100. Asterisk symbols $(*),(* *)$, and $(* * *)$ denote $P<0.05, P<0.01$, and $P<0.001$, respectively, compared to untreated cells.

AFM results. Approximately $75 \%$ of GO sheets were within the range of $100-300 \mathrm{~nm}$ (Figure 1c). The Fourier transform infrared (FT-IR) spectra showed that the peaks at 3421, 2925, $1720,1600-1450$, and $1106 \mathrm{~cm}^{-1}$ were attributed to the vibrations of $\mathrm{O}-\mathrm{H}, \mathrm{C}-\mathrm{H}, \mathrm{C}=\mathrm{O}, \mathrm{C}=\mathrm{C}$, and $\mathrm{C}-\mathrm{O}$ bonds, respectively (Figure 1e). As reflected by the Raman spectroscopy (Figure 1f), a constant Raman shift of the D band ( 1340 $\mathrm{cm}^{-1}$ ) derived from a defect-induced breathing mode of $\mathrm{sp}^{2}$ 
(a)

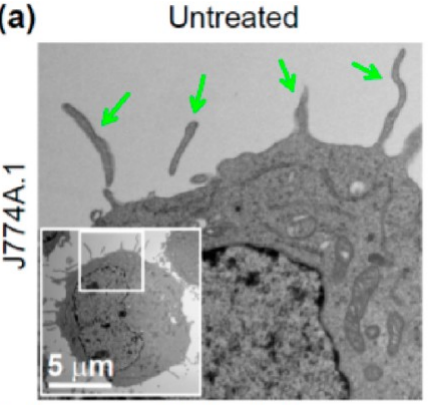

(c)

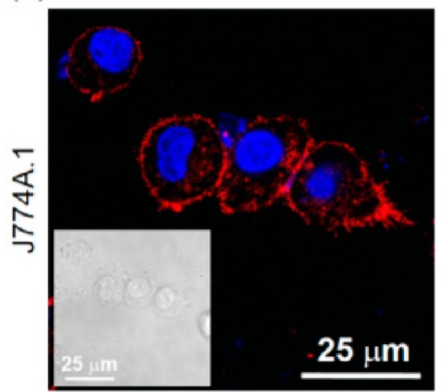

(e)

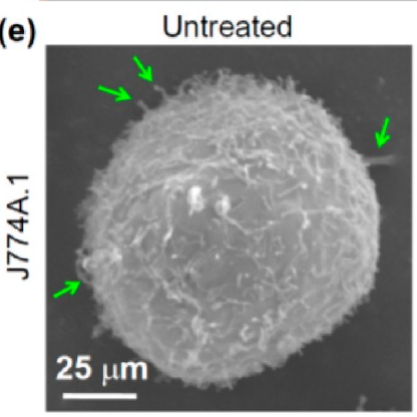

GO-treated (24h)

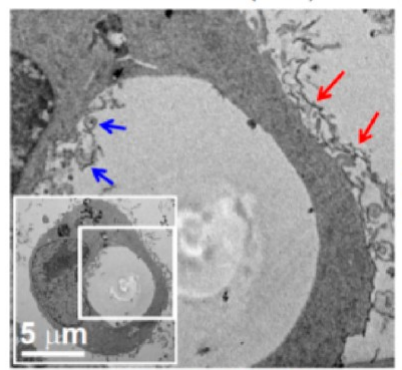

GO-treated (24h)

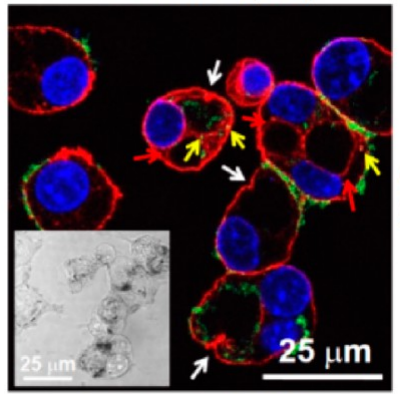

GO-treated (24h)

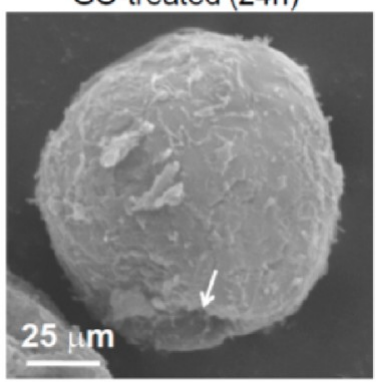

(b)

Untreated

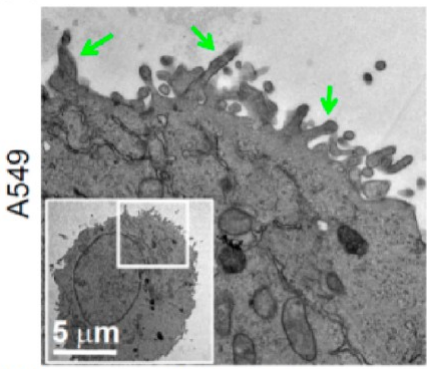

(d)
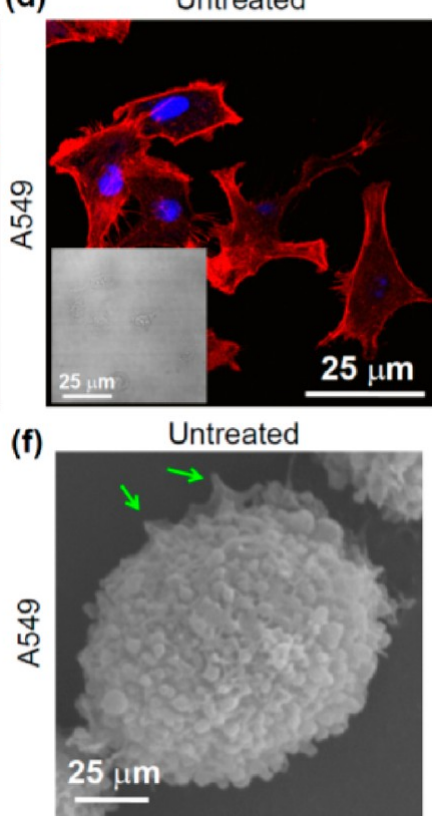

GO-treated (24h)

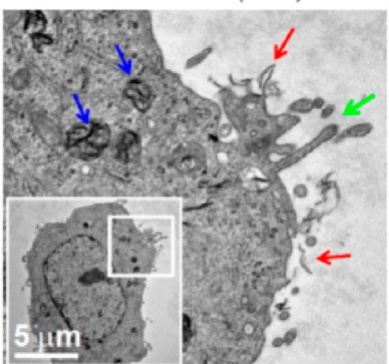

GO-treated (24h)

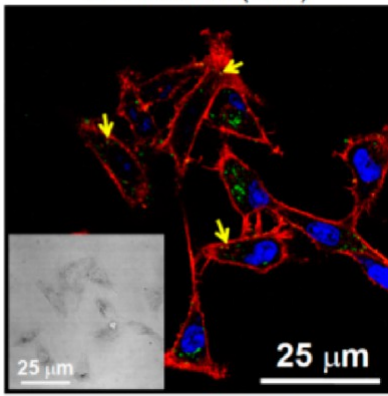

GO-treated (24h)

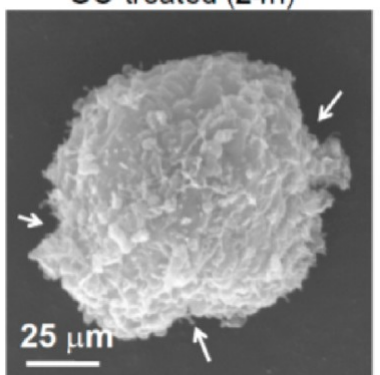

Figure 3. Cellular localization of GO sheets and topographical analysis of plasma membrane. High-resolution TEM images for cellular localization of GO sheets in (a) J774A.1 and (b) A549 cells after $24 \mathrm{~h}$ treatment. Location of GO sheets on the plasma membrane and within the cytosol is denoted by red and blue arrows, respectively. Green arrows show the protrusions on the cell membrane. CLSM images depicting GO localization and membrane morphological and actin meshwork alterations of (c) J774A.1 and (d) A549 cells following GO treatment for $24 \mathrm{~h}$. Cells were treated with FITC-BSA-labeled GO (in green) for $24 \mathrm{~h}$ and were then subjected to cytoskeleton staining with rhodaminephalloidin (in red) and nuclear staining with DAPI (in blue). Red arrows mark the membrane-bound structures inside cells, namely, phagosomes. White arrows indicate the collapsed plasma membrane. Yellow arrows denote the interaction between GO and actin meshwork. Merged colors for green and red appear in yellow. SEM images of GO-treated (e) J774A.1 and (f) A549 cells. White arrows represent the collapsed plasma membrane. Green arrows indicate the protrusions on the membrane. For the above experiments, J774A.1 and A549 cells were treated with GO at 4 and $10 \mu \mathrm{g} / \mathrm{mL}$ for $24 \mathrm{~h}$, respectively.

rings and the $\mathrm{G}$ band $\left(\sim 1600 \mathrm{~cm}^{-1}\right)$ owing to the vibration of $\mathrm{sp}^{2}$-bonded carbon atoms were observed for our GO materials, with the $I_{\mathrm{D}} / I_{\mathrm{G}}$ value at 1.07 , in agreement with the literature. ${ }^{27}$ Furthermore, as shown in Figure 1g, X-ray photoelectron spectroscopy (XPS) results indicated that the major characteristic peaks of $\mathrm{C} 1 \mathrm{~s}$ spectra included $\mathrm{C}-\mathrm{C} / \mathrm{C}=\mathrm{C}($ at $284.5 \mathrm{eV})$, $\mathrm{C}-\mathrm{OH}$ (at $285.4 \mathrm{eV}$ ), $\mathrm{C}-\mathrm{O}$ (at $286.5 \mathrm{eV}$ ), $\mathrm{C}=\mathrm{O}$ (at 287.8 $\mathrm{eV}$ ), and $\mathrm{O}=\mathrm{C}-\mathrm{C}$ (at $288.6 \mathrm{eV}$ ), indicative of differential surface functional groups on $\mathrm{GO}$ sheets.

Afterward, GO dispersibility in aqueous solutions was determined. In deionized water and cell culture medium, GO materials remained stable and well-dispersed after $24 \mathrm{~h}$ incubation, and no obvious sediment could be observed. After $24 \mathrm{~h}$ incubation in culture medium, the AFM analysis showed that most of GO sheets did not agglomerate into larger particles and the thickness of GO sheets increased to 4-12 nm (Figure S1a,b), likely due to the formation of a protein corona on their surface. ${ }^{27}$ The hydrodynamic diameter and polydispersity index measurements further demonstrated that the adsorption of proteins increased the size of GO sheets and slightly changed its dispersion in culture medium after $48 \mathrm{~h}$ (Figure S1c,d). Meanwhile, the GO sheets were negatively charged in both water and culture medium, with a $\zeta$-potential at $-38.9 \pm 0.7$ and $-7.5 \pm 0.6 \mathrm{mV}$, respectively, consistent with previous results. ${ }^{27}$

Identification of Sublethal Concentrations that Interfered in Cellular Priming State. To elucidate the molecular basis underlying GO-induced alterations to the cellular priming state, two cell types, macrophages and lung cancer cells, were used in this study. The murine J774A.1 macrophages and A549 lung cancer cells (a human lung epithelial carcinoma cells, representative of a NSCLC cell model) were subjected to cytotoxicity screening upon GO treatment. As shown in Figure 2a,b, GO did not elicit significant cytotoxicity to J774A.1 cells and A549 cells at concentrations below 10 and $50 \mu \mathrm{g} / \mathrm{mL}$, respectively. The lethal dose $50\left(\mathrm{LD}_{50}\right)$ values were $c a .50$ and $75 \mu \mathrm{g} / \mathrm{mL}$ for J774A.1 and A549 cells, respectively. Since significant cell death might complicate the investigation of the 
(a)

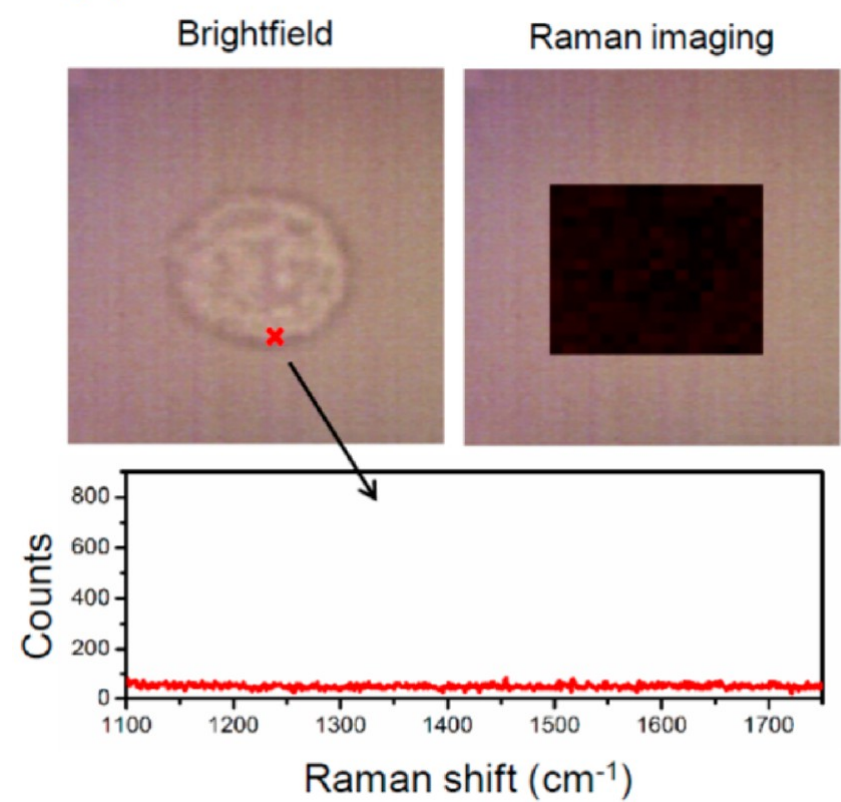

(c)

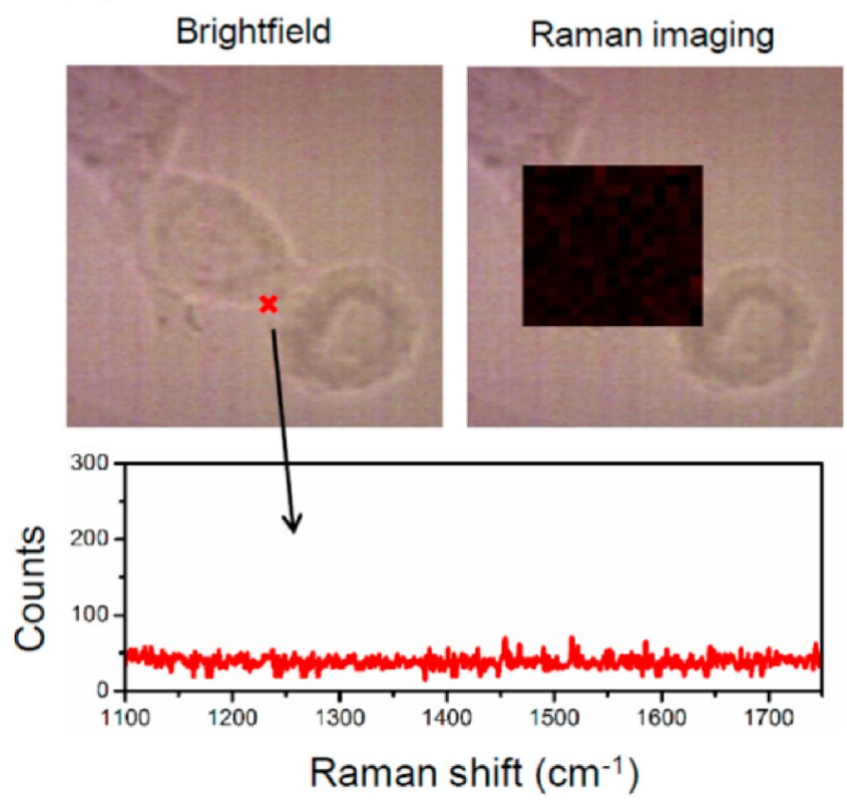

(b)

GO-treated J774A.1

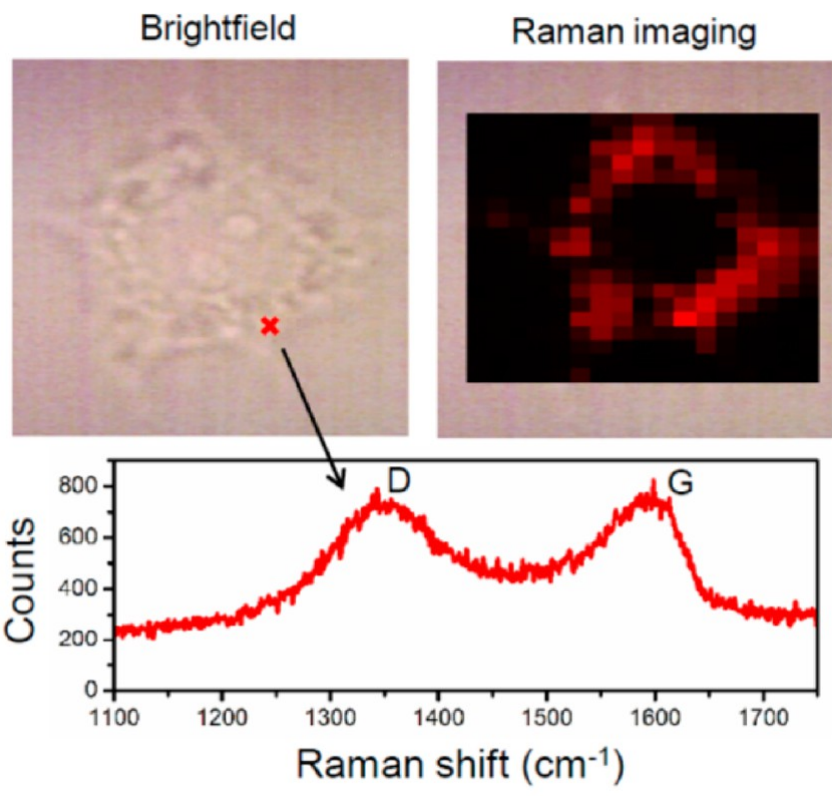

(d)
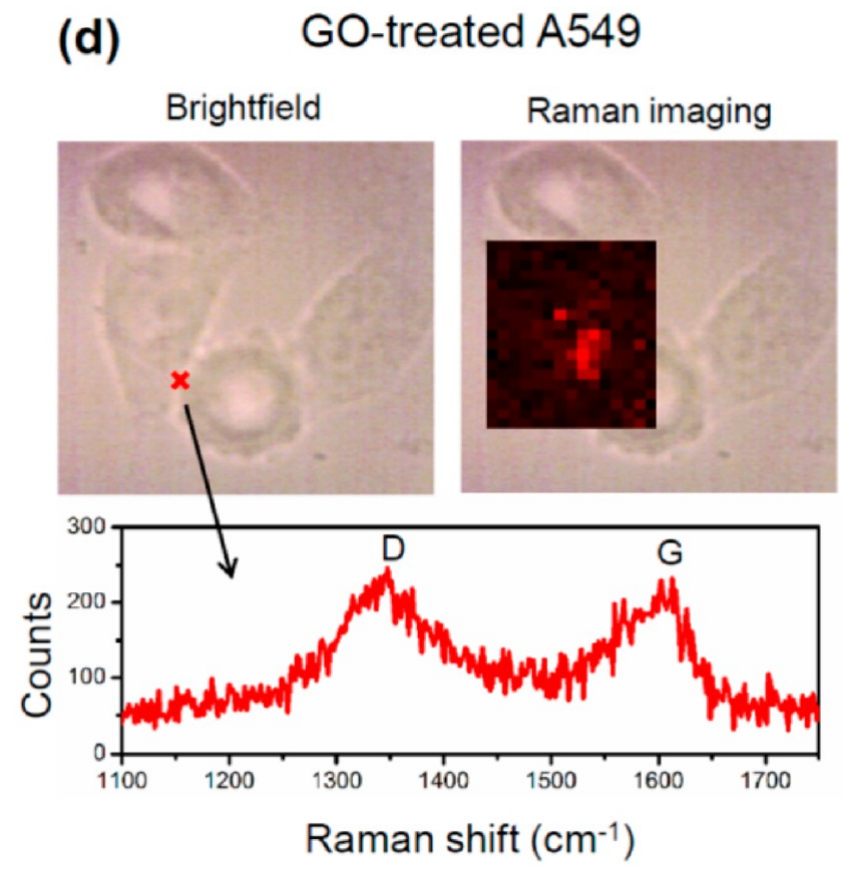

Figure 4. Cellular localization of GO determined by Raman microscopy. Raman images for cellular localization of GO in (a,b) J774A.1 and (c,d) A549 cells. A Raman spectrum was acquired from the location of the red cross for each cell. J774A.1 and A549 cells were treated with GO for $24 \mathrm{~h}$ at 4 and $10 \mu \mathrm{g} / \mathrm{mL}$, respectively.

interplay between GO and the plasma membrane, sublethal GO concentrations were selected for J774A.1 $(4 \mu \mathrm{g} / \mathrm{mL})$ and A549 $(10 \mu \mathrm{g} / \mathrm{mL})$ in the following experiments.

GO Treatment Changed Membrane Permeability, Cellular Morphology, and Priming State. Regarding the investigation of the interplay between GO-plasma membrane interactions and cellular priming state, we focused here on the plasma membrane, cytoskeleton, and ion transportation. First, the permeability of the cell membrane was assessed through propidium iodide (PI) staining, TO-PRO-3 staining, and lactate dehydrogenase (LDH) assay. For J774A.1 cells, the membrane permeability increased following GO treatment at $4 \mu \mathrm{g} / \mathrm{mL}$ for 6 and $24 \mathrm{~h}$, especially for the $24 \mathrm{~h}$ treatment, as reflected by the PI and TO-PRO-3 staining results (Figures $2 \mathrm{c}$ and S2). Similarly, the membrane permeability was also elevated in A549 cells upon GO exposure, compared to untreated cells (Figures $2 \mathrm{~d}$ and S2). In support of the PI and TO-PRO-3 staining data, significant $\mathrm{LDH}$ release was observed in both cell types in a dose-dependent manner (Figure 2e,f, $P<0.05$ ). Thereafter, the interaction between GO sheets and cells was examined through TEM, Raman, confocal laser scanning microscopy (CLSM), and SEM. As shown in Figure 3a,b, TEM images revealed that 
(a)
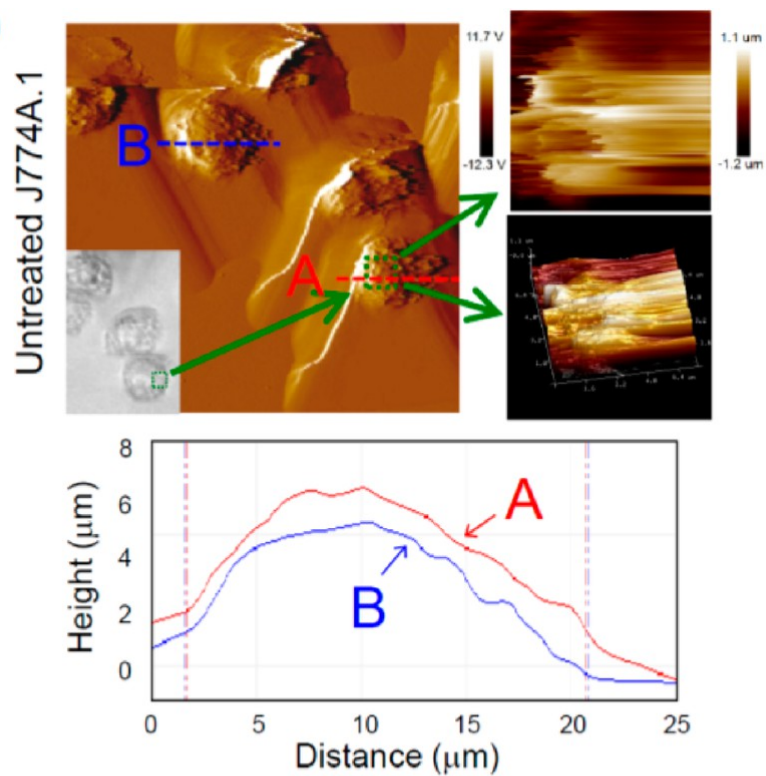

(c)
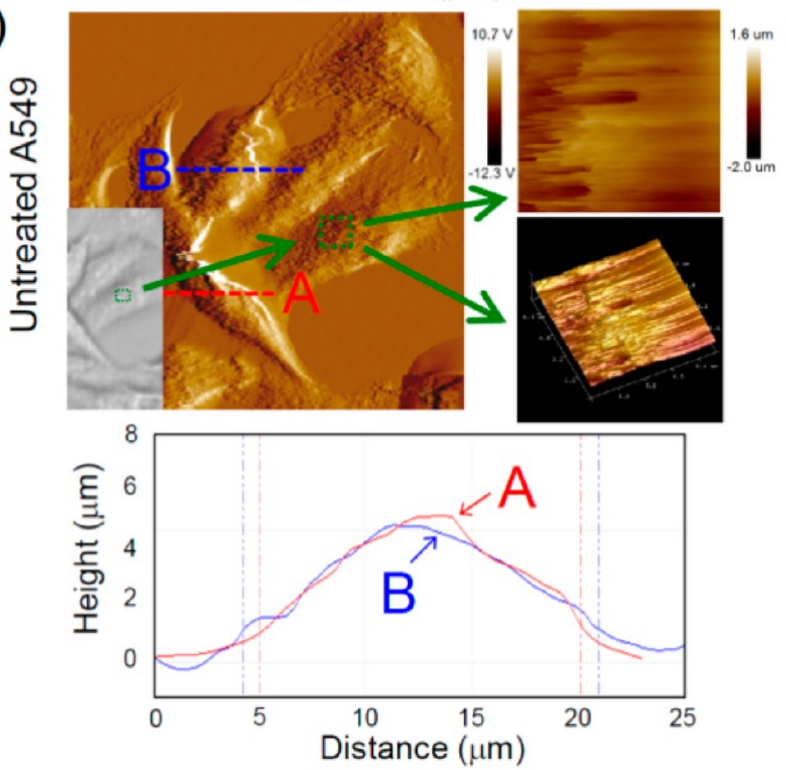

(b)
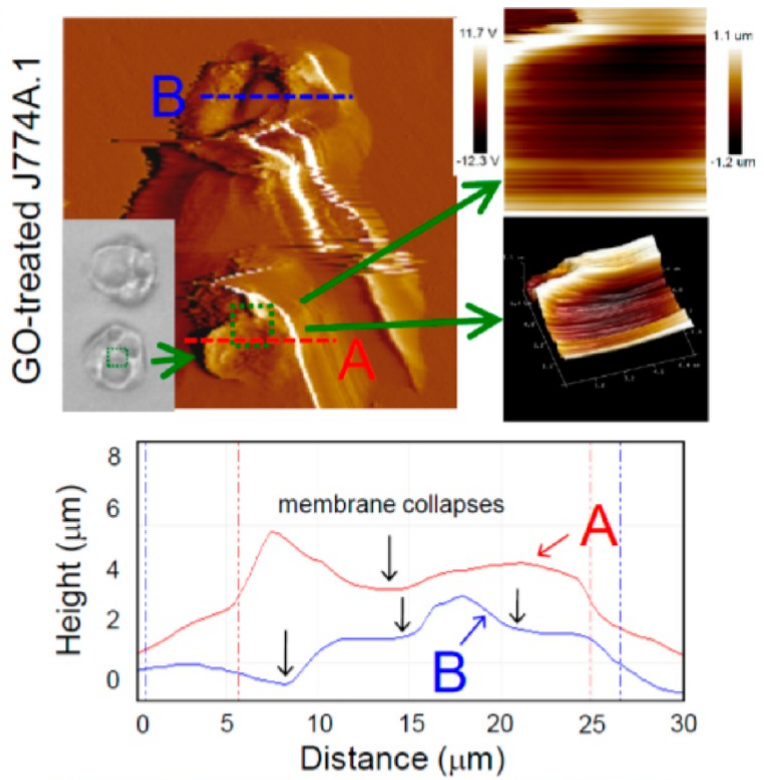

(d)
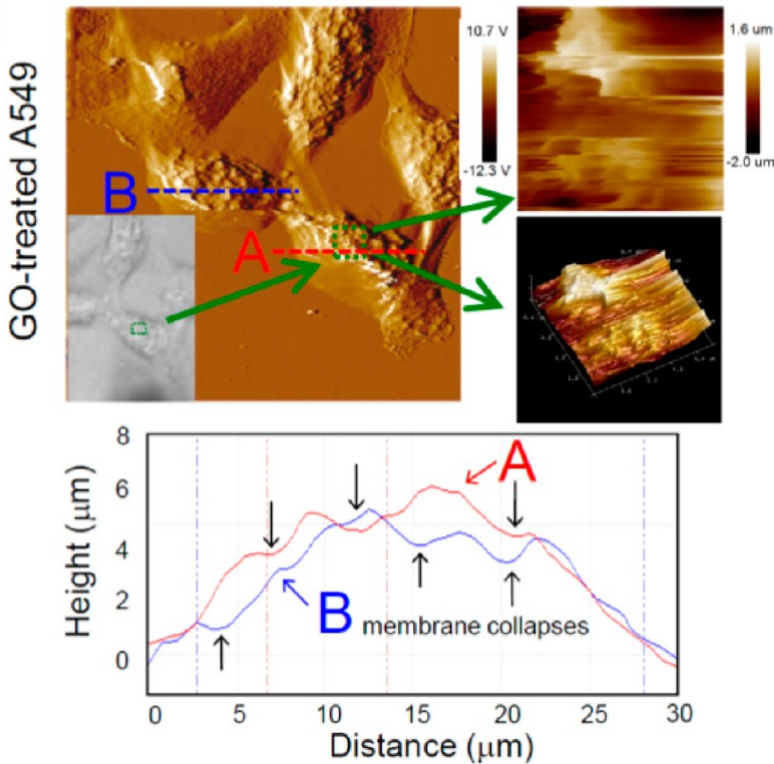

Figure 5. Topographical analysis of (a,c) untreated and (b,d) GO-treated cellular plasma membranes by AFM. J774A.1 and A549 cells were treated with GO at 4 and $10 \mu \mathrm{g} / \mathrm{mL}$ for $24 \mathrm{~h}$, respectively. Thereafter, cells were imaged by a phase contrast microscopy and determined for 2D/3D topographical analysis by AFM. The 2D/3D topography of cellular plasma membranes in green dotted squares was shown in the top right in $(\mathrm{a}-\mathrm{d})$. The red $(\mathrm{A})$ and blue (B) dotted lines represent the scanning positions for the height profiles of two individual J774A.1 and A549 cells, and their corresponding height profiles are shown in the bottom in $(a-d)$. The black arrows indicate the membrane collapses of GO-treated J774A.1 and A549 cells.

GO sheets were mainly located in membrane-bound structures inside cells (most likely in phagosomes within the cytosol, as denoted by blue arrows) and on plasma membrane (indicted by red arrows) in both J774A.1 and A549 cells. These findings were further validated through Raman imaging (Figure 4). These data hence indicated an active interaction of GO sheets with plasma membrane. As shown in Figure 3a,b, GO sheets might exist in monolayer and multiple layers, due to the formation of multiple-layer GO sheets with the aid of protein and DNA molecules. ${ }^{30,31}$ GO sheets may form multiple layer sheets in culture medium or directly on the plasma membrane. In culture medium, GO sheets might associate to one another through proteins (e.g., BSA) or other biomolecules (e.g., DNA), leading to the formation of multiple layers and nanoparticles. $^{30,31}$ Furthermore, this association might occur on the plasma membrane, resulting in the stacking and binding of GO sheets on the membrane. To this end, we would assume that GO sheets on the cell membrane existed in monolayer and multiple layers, as well, as shown in Figure 3.

To substantiate the above findings and further delineate the impact of this interaction on membrane integrity, fluorescein isothiocyanate-bovine serum albumin (FITC-BSA)-labeled GO was tracked following exposure together with cytoskeleton staining with rhodamine-phalloidin (in red) and nuclear staining with 4',6-diamidino-2-phenylindole dihydrochloride (DAPI, in blue). After $24 \mathrm{~h}$ treatment (Figure 3c,d), GO sheets (in green) could be visualized on the membrane and inside cells for both J774A.1 and A549, consistent with the TEM results. Moreover, association between GO and actin fibers could be visualized in GO-treated cells, as evidenced by the CLSM 
(a)

Regulation of actin cytoskeleton

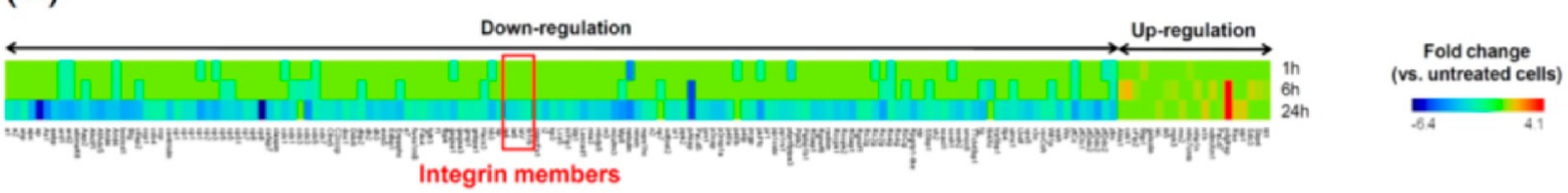

Focal adhesion

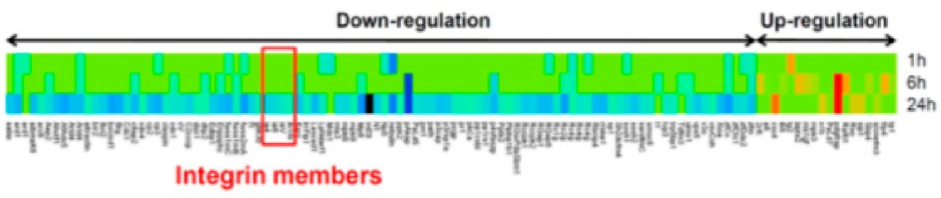

Vascular smooth muscle contraction

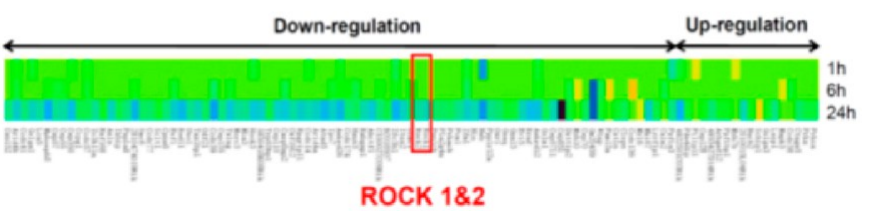

Tight junction

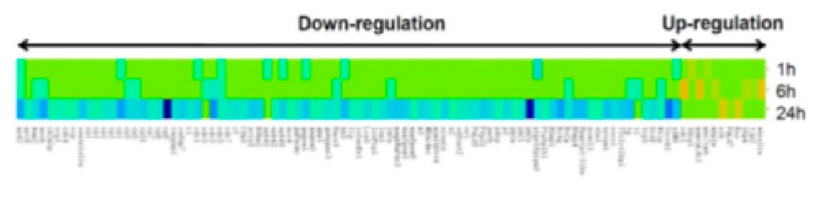

(b)

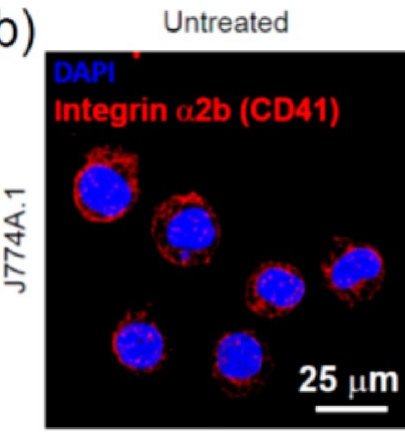

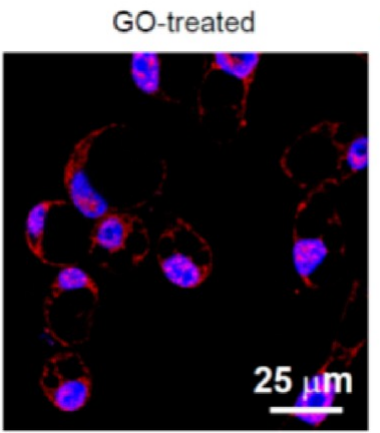

(c)

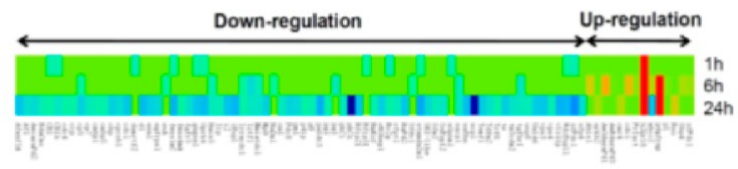

Endocytosis
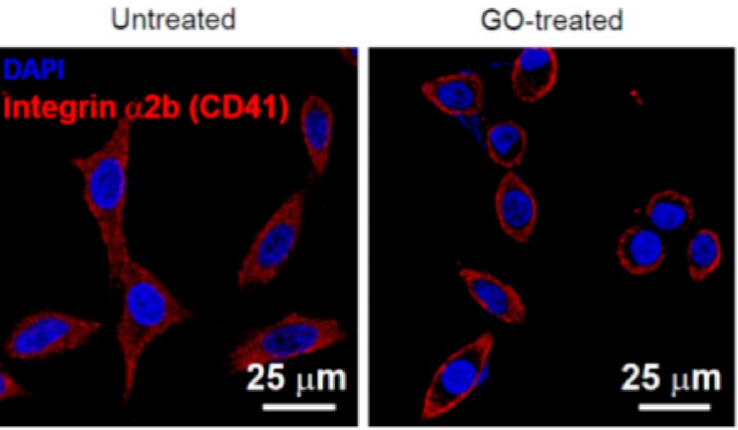

Figure 6. Gene expression signature affected by GO treatment. (a) Heatmaps representing differentially expressed genes in response to GO. J774A.1 cells were treated with GO at $4 \mu \mathrm{g} / \mathrm{mL}$ for 1,6 , and $24 \mathrm{~h}$, and gene expression profiles were analyzed based on RNA-Seq analysis. A $\log _{2}$ fold change was used to characterize the gene expression changes of GO-treated cells, compared to untreated cells. Genes responsible for the regulation of actin cytoskeleton, focal adhesion, vascular smooth muscle contraction, tight junction, and endocytosis were selected for presentation here. The genes encoding integrin and ROCK members are highlighted in red rectangles. (b,c) Immunofluorescent staining of integrin $\alpha 2 \mathrm{~b}$ (CD41, in red) on the plasma membrane upon GO by CLSM analysis. (b) J774A.1 and (c) A549 cells were treated with GO at 4 and $10 \mu \mathrm{g} / \mathrm{mL}$ for $24 \mathrm{~h}$, respectively, followed by CLSM analysis. Nuclei were stained with DAPI in blue.

images (indicted by yellow arrows in Figure 3c,d). Compared to A549 epithelial cells, J774A.1 macrophages had more GO association on the plasma membrane and more uptake inside cells due to active phagocytosis, leading to a large empty or collapsed space within the cytoplasmic region after $24 \mathrm{~h}$ treatment (Figure 3c). As a result, the size of J774A.1 was increased by 22 and $37 \%$ after 6 and $24 \mathrm{~h}$ treatment, compared to the untreated cells (Figure S3, $P<0.001$ ), respectively, indicative of cellular swelling. Milder morphological alterations were found for A549 cells in comparison to J774A.1 cells (Figure 3d). Nonetheless, we observed disassembly of actin fibers and reduction of stress fiber formation with reduced density of actin meshwork in A549 cells following GO treatment, especially at $24 \mathrm{~h}$ (Figure $3 \mathrm{~d}$ ), suggestive of an impaired cytoskeleton. SEM analysis also verified dramatic membrane collapse in GO-treated cells (indicated by white arrows) for both J774A.1 and A549 (Figure 3e,f). The collapsed membrane of GO-treated cells is a pronounced feature of cellular morphological changes found by us, which has not been reported previously to our knowledge. This feature pinpointed the breakdown and loss of membrane cytoskeletal networks.
This featured alteration was uniformly found in J774A.1 and A549 cells, as the percentages of cells with deformed morphology were approximately 46 and $30 \%$ after $24 \mathrm{~h} \mathrm{GO}$ treatment $(n>70)$, respectively.

Moreover, membrane surface protrusions and mechanical alignments were compromised in GO-treated cells (denoted by green arrows in Figure 3a,b,e,f). Furthermore, we examined the plasma membrane topography of GO-treated cells through AFM (Figure 5). The representative AFM images showed that GO treatment significantly affected the topography of the plasma membrane for both J774A.1 and A549 cells. For GOtreated J774A.1 cells, dramatic membrane collapses occurred, and the quantitative data revealed a ca. 2-3 $\mu \mathrm{m}$ decline of cellular height, compared to untreated cells (Figure 5a,b). For GO-treated A549 cells, the surface roughness of the plasma membrane was induced with the appearance of many small collapses (1-2 $\mu \mathrm{m}$ membrane collapses), compared to untreated cells (Figure $5 c, d$ ), consistent with the SEM results (Figure 3f). This finding revealed that $\mathrm{GO}$ induced considerable membrane collapses and cytoskeletal disorders in GO-treated cells. Together, these results demonstrated that 
GO was strongly associated with the plasma membrane, resulting in a loss of membrane integrity and damage to the cytoskeletal meshwork.

Molecular Basis Underlying GO-Mediated Impairments to the Membrane and Cytoskeleton. To look for the molecular mechanisms underlying GO-induced impairments to the membrane and cytoskeleton, RNA-Seq transcriptome analysis was carried out in J774A.1 cells following GO treatment. RNA-Seq analysis uncovered a large number of differentially expressed genes upon GO exposure. To better understand the gene expression changes, we endeavored to lay out the expression profiles of these differentially expressed genes based on their functions in GO-treated cells over the time course at 1,6 , and $24 \mathrm{~h}$, relative to untreated cells. As characterized in the heatmaps (Figure 6a), most genes were down-regulated in GO-treated cells, and the down-regulation trend became more remarkable at $24 \mathrm{~h}$ after GO treatment. Gene ontology analysis unearthed that a wide array of signaling pathways were affected in GO-treated cells, and the top 10 signaling pathways are described in Table 1 . Among these, five

Table 1. Top 10 Affected Pathways in J774A.1 Cells Responding to GO Treatment

\begin{tabular}{rlc} 
no. & \multicolumn{1}{c}{ pathway } & $\begin{array}{c}\text { number of differentially } \\
\text { expressed genes }\end{array}$ \\
1 & metabolic pathways & 170 \\
2 & regulation of actin cytoskeleton & 148 \\
3 & focal adhesion & 99 \\
4 & vascular smooth muscle contraction & 95 \\
5 & RNA transport & 88 \\
6 & tight junction & 86 \\
7 & pathways in cancer development & 83 \\
8 & endocytosis & 73 \\
9 & transcriptional misregulation involved & 64 \\
& in diseases & 62 \\
\hline
\end{tabular}

pathways (i.e., regulation of actin cytoskeleton, focal adhesion, vascular smooth muscle contraction, tight junction, and endocytosis) were closely related to the functions of plasma membrane and cytoskeleton. These findings were in agreement with the pronounced features of cellular morphology for GOtreated cells (namely, collapsed membrane and damaged cytoskeleton) (Figures 3 and 5). To define the underlying molecular mechanisms, further mechanistic investigation was carried out based on the transcriptome results. To this end, integrin and ROCK were selected because they are well-known for their important roles in sustaining the plasma membrane and cytoskeleton.

To substantiate the RNA-Seq results, we validated the changes of a few differentially expressed genes and associated molecules that were crucial for the maintenance of the membrane and cytoskeleton at the protein level. Integrins are transmembrane receptors, consisting of two different chains, namely, $\alpha$ and $\beta$ subunits, and integrin family members play a crucial role in maintaining the cytoskeletal meshwork and in conducting signaling transduction. ${ }^{32,33}$ As transmembrane proteins, integrins link membrane and intracellular actin meshwork to the extracellular matrix (ECM) and signaling complexes and thus orchestrate cells to be adapted to their extracellular microenvironment. ${ }^{34,35}$ However, disordered expression of integrins would impair cellular morphology, focal adhesion, migration, and functions. ${ }^{36,37}$ In analogy to the RNA-
Seq data, the protein levels of integrins were greatly diminished in GO-treated cells, as reflected by the immunofluorescence microscopy analysis (shown in red color, Figure $6 \mathrm{~b}, \mathrm{c}$ ) and Western blot analysis (Figure 7a,b). There are $18 \alpha$ (e.g., $\alpha 2 \mathrm{~b}$ subunit, namely, CD41) and $8 \beta$ subunits (e.g., $\beta 1$ subunit, namely, CD29). Western blot analysis confirmed the reduction of integrin proteins in GO-treated cells in a dose-dependent manner for both J774A.1 and A549 cells, relative to untreated cells (Figure $7 \mathrm{a}, \mathrm{b}$ ). To validate the occurrence of a GOintegrin interaction and the resulting activation of the integrinFAK-Rho-ROCK signaling, the important integrin-associated dual kinase complex, FAK/Src, was studied by Western blot analysis (Figure S4). The FAK/Src complex can be recruited and activated by integrins to initiate a cascade of phosphorylation events in order to trigger downstream signaling to impact cellular behaviors, such as cell survival, proliferation, and migration. ${ }^{38,39}$ As shown in Figure S4, after 6 h GO treatment, the signal initiated by the GO-integrin interaction was transduced into cells through the activation of FAK/Src complex dependent on their increased phosphorylation (namely, increased levels of p-FAK and p-Src). Therefore, we uncovered that GO could activate the integrin-FAK-RhoROCK pathway, which fundamentally dictated cellular morphological changes (Figures 6, 7, and S4). For J774.A1 cells, the increase of p-FAK and p-Src was approximately $30 \%$, and the elevation for p-FAK and p-Src in A549 cells was over 50\% (Figure S4a,b).

When subjected to the binding of its ligands to integrin, FAK could be recruited and activated, leading to the activation of other associated partners, such as talin, paxillin, vinculin, $\mathrm{SH} 3$, and Src, all together known as the focal adhesion complex. ${ }^{38,39}$ Downstream of integrin-FAK activation, small GTPase signaling, including Rho family members (i.e., RhoA, Racl, and Cdc42), ${ }^{40,41}$ can be activated to drive actin cytoskeletal remodeling and cell motility, proliferation, and survival in response to exotic stresses. ${ }^{42}$ The Rho GTPase is a family of small signaling $G$ proteins and has been proven to be crucial for the regulation of intracellular actin dynamics and morphology maintainance. $^{40,41}$ In agreement with the decline of integrin protein levels (Figure 7a,b), FAK protein concentration was diminished in a dose-dependent manner after $24 \mathrm{~h}$ GO treatment in J774A.1 and A549 cells (Figure 7a,b). Furthermore, we assessed the levels of the Rho family members and their substrate ROCK (including ROCK1 and ROCK2), a direct downstream effector of Rho to conduct the formation of stress fibers and focal adhesions by phosphorylating myosin light chain. ${ }^{43}$ As shown in Figure $7 c$, the protein levels of RhoA, Rac1, Cdc42, ROCK1, and ROCK2 were diminished in J774A.1 upon GO treatment in a dose-dependent manner. Moreover, similar results were observed in A549 cells, but to a less extent, except for $\mathrm{Cdc} 42$ (Figure $7 \mathrm{~d}$ ). The decline of intracellular ROCK activity in GO-treated cells also confirmed the above findings (Figure $7 \mathrm{e}, P<0.05$ ).

Furthermore, we performed the stable knocking-down of integrin $\alpha 2 \mathrm{~b}$ using the approach of shRNA (stable transfectants $\# 1$ and \#2), as evidenced by reduced integrin $\alpha 2 \mathrm{~b}$ as well as ROCK1 and ROCK2 mass (Figure 7f). These data showed that the levels of ROCK1 and ROCK2 were closely subjected to the regulation by integrin $\alpha 2 \mathrm{~b}$. Reduced ROCK1 and ROCK2 expressions would eventually lead to disassembly of actin fibers and decrease of stress fiber formation with the compromised density of actin meshwork, as shown in Figure 3c,d. On the flip side, overexpression of integrin $\alpha 2 \mathrm{~b}$ in A549 cells led to 


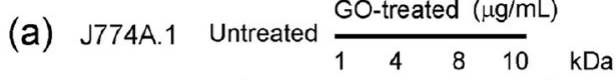
Integrin $\alpha 2 b(C D 41) \square-125$

FAK

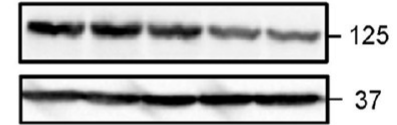

$\mathrm{GAPDH}$

37

(c)

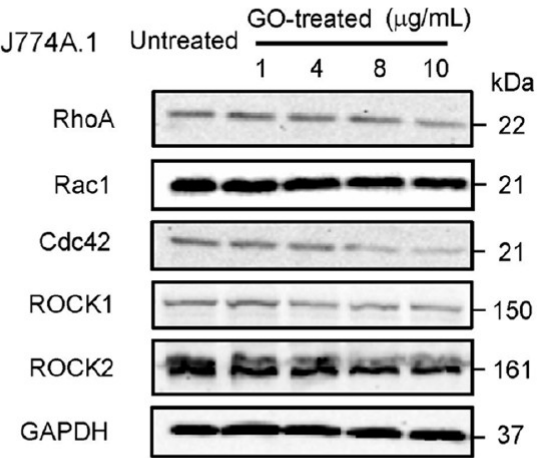

(e)
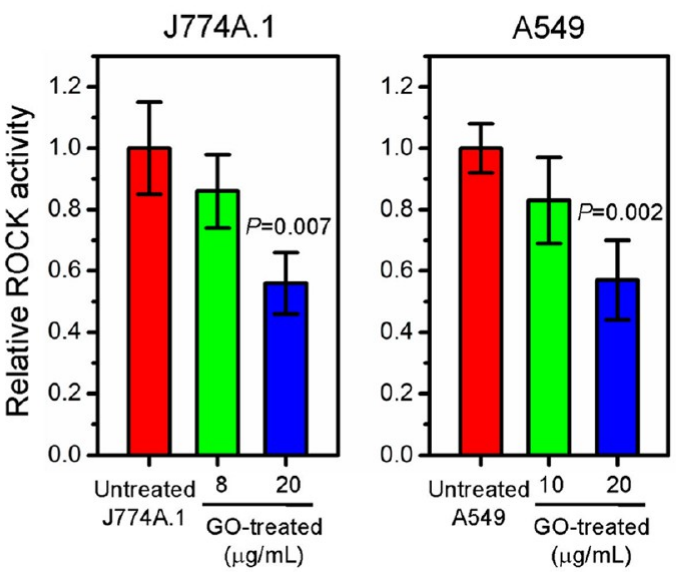

(f)

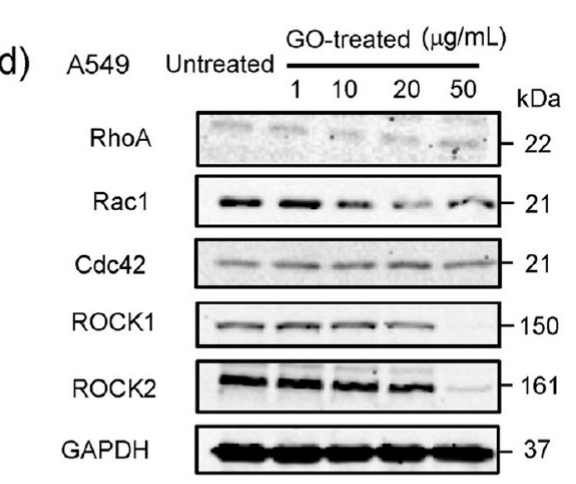

(g)

$\mathrm{GO}+$ $\frac{\mathrm{GO}-}{\mathrm{VC} 1 \mathrm{O}} \frac{(20 \mu \mathrm{g} / \mathrm{mL})}{\mathrm{VC} / \mathrm{O}}$

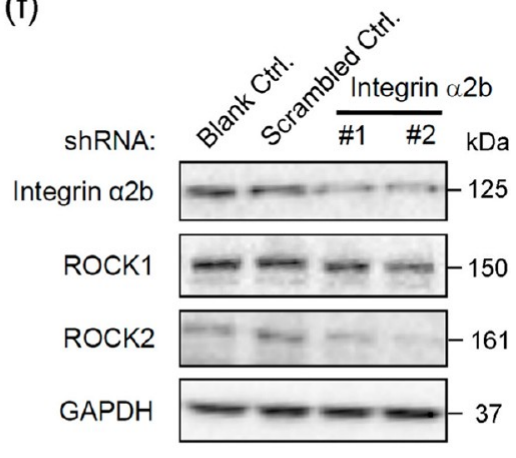

Integrin $\alpha 2 \mathrm{~b}(\mathrm{CD} 41) \square-\square-125$

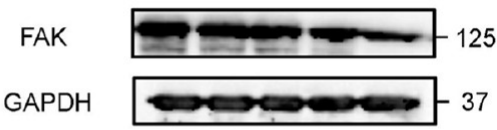

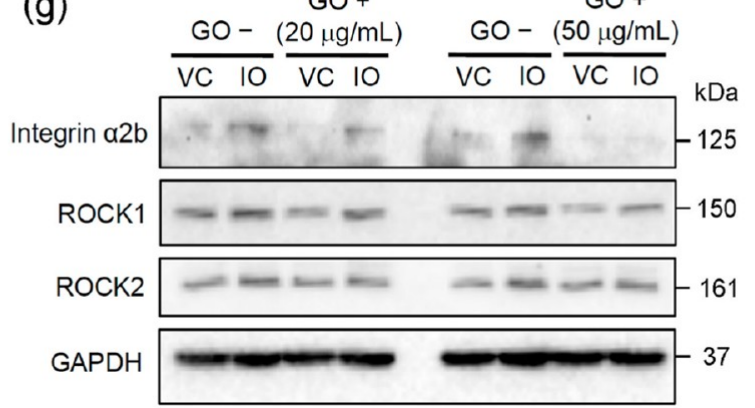

Figure 7. Alterations of proteins involved in integrin-FAK-Rho-ROCK signaling upon GO treatment. (a-d) Western blot analysis of integrin $\alpha 2 \mathrm{~b}$ (CD41), FAK, RhoA, Rac1, Cdc42, ROCK1, and ROCK2 in J774A.1 and A549 cells after 24 h GO treatment at different concentrations. (e) ROCK activities in J774A.1 and A549 cells upon GO treatment (8 and $20 \mu \mathrm{g} / \mathrm{mL}$ for J774A.1; 10 and $20 \mu \mathrm{g} / \mathrm{mL}$ for A549) for $24 \mathrm{~h}(n=4)$. (f) Integrin $\alpha 2 \mathrm{~b}$ regulates the levels of ROCK1 and ROCK2. A549 cells were transfected with lentiviral particles for shRNA expression to selectively knock down integrin $\alpha 2 b$. Here, two stable knockdown transfectants were used, termed as shRNA \#1 and \#2, and their integrin $\alpha 2 \mathrm{~b}$ and ROCK protein levels were examined by Western blotting. (g) Overexpression of integrin $\alpha 2 \mathrm{~b}$ increases ROCK level in GO-treated A549 cells. Overexpression of integrin $\alpha 2 b$ in A549 cells was achieved using a pLent-EF1a-FH-CMV-GP vector. Cells with integrin $\alpha 2 \mathrm{~b}$ overexpression vector or control vector were treated with $\mathrm{GO}$ at 20 and $50 \mu \mathrm{g} / \mathrm{mL}$ for $24 \mathrm{~h}$, respectively. The mass of integrin $\alpha 2 b$ and ROCK1 and ROCK2 proteins was determined by Western blotting. VC denotes vector control. IO represents integrin $\alpha 2 b$ overexpression.

increased levels of integrin $\alpha 2 \mathrm{~b}$ and ROCK proteins (Figure $7 \mathrm{~g}$ ). Consequently, the reduction of ROCK (namely, ROCK1 and ROCK2) due to GO treatment was markedly reversed in integrin $\alpha 2 \mathrm{~b}$-overexpressing cells, relative to that in vector control cells (Figure $7 \mathrm{~g}$ ). To this end, overexpression of integrin $\alpha 2 \mathrm{~b}$ could also significantly rescue the phenotype in the GO-treated cells. These results thus highlighted our finding that GO compromised the levels of integrin and thereby 
(a)

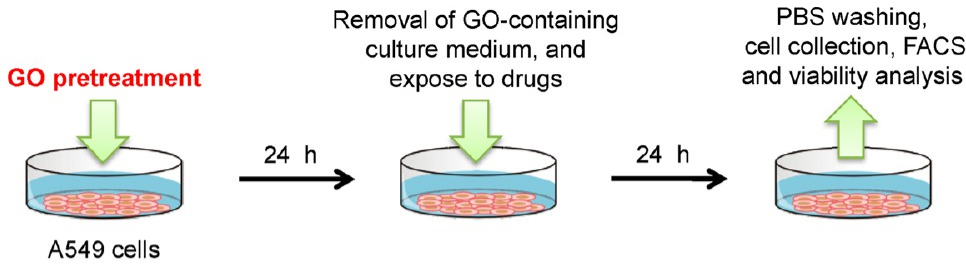

(b)
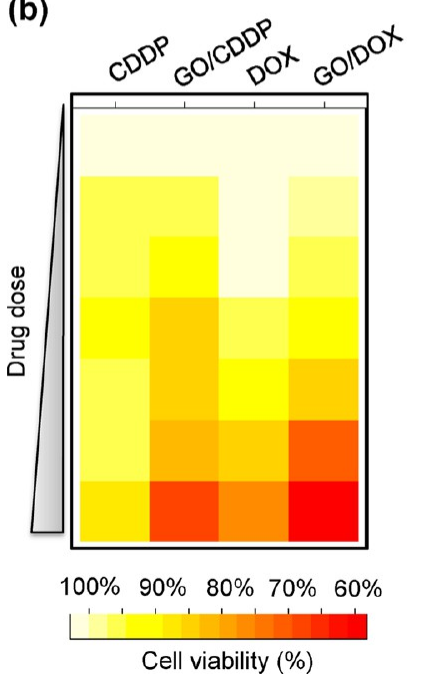

(c)

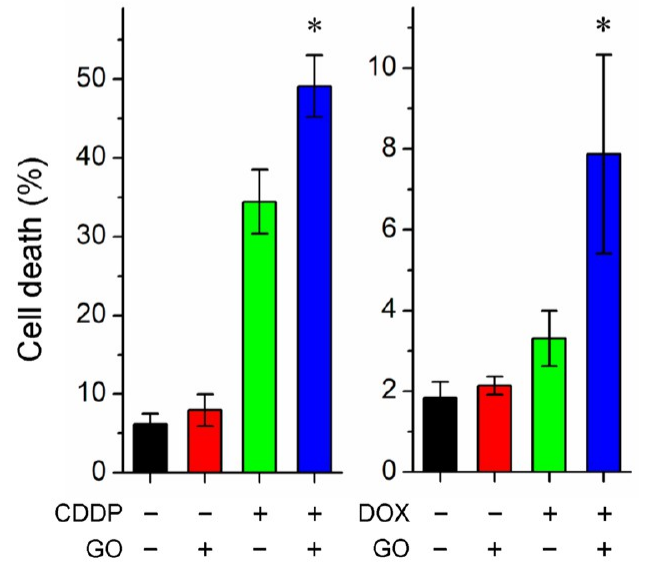

Figure 8. GO-induced sensitization to A549 cells responding to DOX and CDDP treatment. (a) Schematic diagram illustrating the experimental design. (b) Heatmap of cell viability after $\operatorname{CDDP}(1,5,10,15,20,30$, and $50 \mu \mathrm{M})$ and $\mathrm{DOX}(0.01,0.05,0.1,0.5,1,2$, and $4 \mu \mathrm{M})$ treatment with or without GO pretreatment at $10 \mu \mathrm{g} / \mathrm{mL}$. (c) Quantified data for cell death determined by FACS analysis with FITC-Annexin $\mathrm{V}$ and PI staining. A549 cells were pretreated with GO at $10 \mu \mathrm{g} / \mathrm{mL}$ for $24 \mathrm{~h}$, followed by PBS washing, and were then exposed to CDDP and DOX at 20 and $0.1 \mu \mathrm{M}$ for $24 \mathrm{~h}(n=4)$, respectively. For comparison, A549 cells were also individually treated with GO at the same concentrations $(n=4)$. Asterisk $(*)$ denotes $P<0.05$, compared to untreated cells.

undermined the FAK-Rho-ROCK signaling pathway. Collectively, we deciphered (at least in part) the molecular basis responsible for GO-induced changes to membrane and cytoskeletal meshwork: GO impaired integrin-FAK-RhoROCK signaling in maintaining the plasma membrane integrity and in driving stress actin fiber formation. Certainly, other affected signaling pathways may contribute to the changes in the cellular priming state responding to GO treatment, which needs detailed investigation in the future. It is reported that integrins expressed on tumor cells and tumor-associated host cells significantly affect tumor progression (such as proliferation, migration, and survival), which suggests integrins as an appealing target in cancer therapeutics for various cancers including lung and breast cancers. ${ }^{44,45}$ Thus far, antagonists against integrins have been tested to inhibit their activities in cancer treatment. ${ }^{45-48}$ Furthermore, antagonists of integrins have also been developed to enhance the efficacy of chemotherapy. ${ }^{49-51}$ In addition to integrins, inhibitors for FAK and ROCK also showed potential to suppress tumor growth and metastasis. ${ }^{52-56}$ Hence, the integrin-FAK-RhoROCK signaling pathway represents a promising target for cancer therapeutics including chemosensitization.

GO Sensitized Cancer Cells to DOX and CDDP through Enhancing Cell Death. The above findings implied a rationale of using $\mathrm{GO}$ to sensitize cancer cells to chemotherapeutic agents due to GO's ability to compromise the membrane integrity and signaling transduction within the interface between membrane and cytoskeleton. Specifically, GO may enhance the sensitivity of A549 cancer cells to chemotherapeutic agents through the mechanism that we discovered above. To test this hypothesis, we pretreated A549 cells with $\mathrm{GO}$ at $10 \mu \mathrm{g} / \mathrm{mL}$ for $24 \mathrm{~h}$ and then exposed cells to DOX and CDDP after removing GO-containing culture medium, followed by cell viability and fluorescence-activated cell sorting (FACS) determinations. The experimental design is depicted in Figure 8a. DOX and CDDP were chosen because they were classical chemotherapeutic drugs to treat human lung cancers including NSCLC. ${ }^{57,58}$ First, cell viability of DOX- and CDDPtreated A549 cells was assessed with or without GO pretreatment. As shown in Figure 8b, the GO-pretreated cells were more sensitive to DOX $(1-4 \mu \mathrm{M})$ and CDDP (15-50 $\mu \mathrm{M})$ with further $10-20 \%$ decline of cell viability, compared to the untreated cells $(P<0.05)$. Thereby, cell death was determined through FACS analysis with Annexin-V FITC and PI staining. To avoid overwhelming cytotoxicity from DOX and CDDP, a concentration at 0.1 and $20 \mu \mathrm{M}$ was used, respectively. GO itself did not incur significant cell death (Figure 8c), in analogy to the cytotoxicity assessment, as described in Figure 2b. Compared with individual DOX and CDDP treatment, DOX and CDDP induced greater cell death in GO-pretreated cells compared to that in DOX- or CDDPtreated cells (Figure 8c). In fact, the sensitization of cell death by GO closely depends on the experimental conditions including concentration, treatment time, and cell type. For A549 cells, GO pretreatment instigated an increase of cell death by about 1.5 -fold, compared to cells without GO pretreatment in response to CDDP $(P<0.05)$, whereas a 2.4 -fold increase of cell death was found in cells responding to DOX (Figure 8c, $P$ $<0.05)$. To substantiate this finding, other cancer types were also used (Figure S5). Analogous to results from A549 cells, 


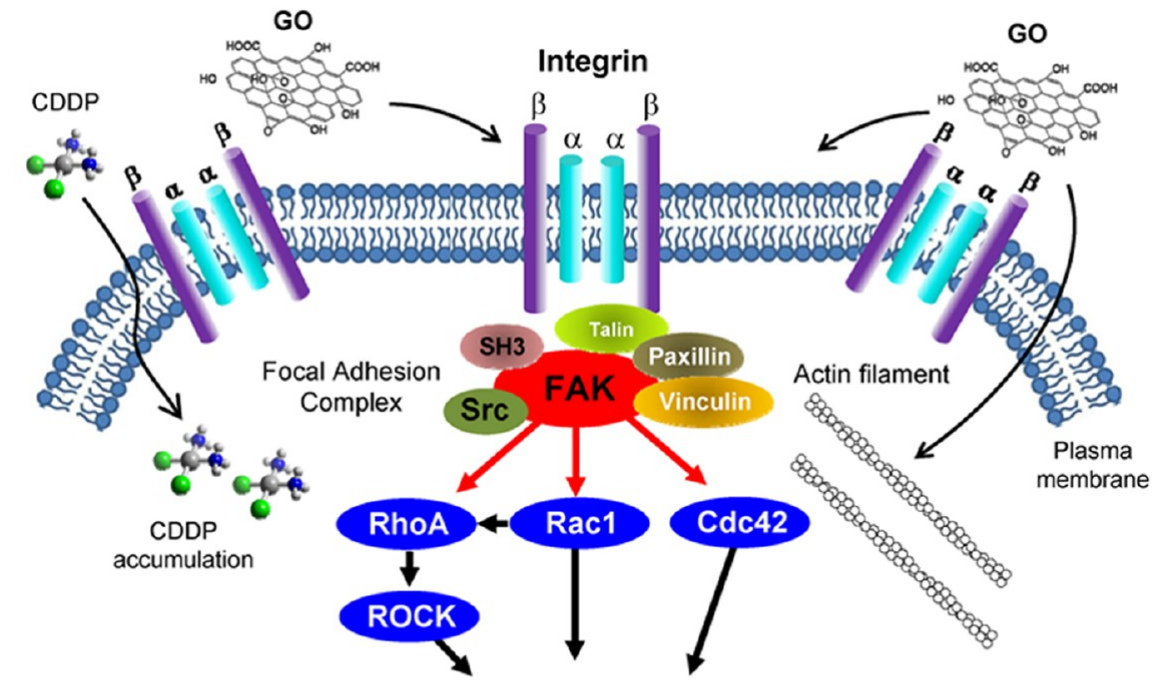

Cell membrane, morphology, adhesion, cytoskeletal dynamics

\section{Membrane integrity $\downarrow$ permeability $\uparrow$ cytoskeletal disruption $\uparrow$}

\section{Chemosensivity $\uparrow$}

Figure 9. Schematic deciphering the molecular basis underlying GO-induced impairments to plasma membrane and cytoskeleton, where integrin-FAK-Rho-ROCK signaling was uncovered to be compromised responding to GO treatment. Based on this mechanism, GO could enhance the chemosensivity of cancer cells to chemotherapeutic agents.

GO pretreatment also sensitized A498 renal and PC3 prostate cancer cells to CDDP by 1.3 -fold and 1.6 -fold relative to cells without GO pretreatment $(P<0.05)$, respectively. Collectively, our data unveiled a finding on GO-mediated sensitization of cancer cells to cytotoxicity induced by therapeutic agents. Nonetheless, further investigations are needed to improve the efficacy of GO sensitization in killing cancer cells.

To elucidate a most important mechanism through which GO sensitized cancer cells to these agents, that is, GO-induced membrane and cytoskeleton damages facilitated CDPP uptake, the intracellular mass of CDDP (indicated by $\mathrm{Pt}$ mass) was determined in cells responding to CDDP at various concentrations following GO pretreatment. As a result, the intracellular Pt mass was increased by $9.6,11.7$, and $17.4 \%$ in response to 4,20 , and $50 \mu \mathrm{g} / \mathrm{mL}$ GO pretreatment, relative to that of untreated cells (Figure S6), respectively. The increase of intracellular CDDP concentration showed in a clear dose dependency, demonstrating that GO pretreatment could enhance CDDP uptake. GO pretreatment could accelerate CDDP influx into cells through various mechanisms including mechanical damages of the cell membrane by direct contact as "nanoknives", $59-61$ disordered ion channels, and endocytic process of the cell membrane. ${ }^{27}$ It should be noted that the increased intracellular mass of CDDP is a vital mechanism underlying the enhanced sensitivity of cancer cells to CDDP; however, other mechanisms could also play a role including compromised alterations to the plasma membrane and cytoskeleton, ion exchange, energy metabolism, etc. In fact, these processes may simultaneously occur. For more implications, this strategy may also apply to more types of solid tumors. In support of the current study, nanomaterials (e.g., gold, zinc oxide, or carbon nanoparticles) were also used to sensitize cancer cells to chemotherapeutic drugs and radiation in order to restrain tumor progression..$^{1,12,62,63}$ Moreover, the threshold of sensitization by GO may vary among different tumor types. Thus, the doses of GO and chemotherapeutic agents should be tailored for different tumors, and more efforts are needed to customize the protocol from this angle of tumor treatment. Local injection at tumor sites would prevent the potential toxicity to normal cells. Optionally, selective targeting of nanomaterials would also increase the efficacy of sensitization and diminish off-target effects to normal cells. Therefore, this strategy could be beneficial for cancer treatment because it could reduce the side effects of chemotherapeutic agents by decreasing dosage or shortening treatment duration due to chemosensitization effect of $\mathrm{GO}$.

\section{CONCLUSIONS}

In this study, we deciphered an important mechanism responsible for GO-induced plasma injuries and cytoskeletal damages: GO treatment undermined the signaling transduction of integrin-FAK-Rho-ROCK in enhancing plasma membrane and stress actin fiber assembly dynamics, leading to plasma membrane perturbation. Toxicogenomic investigations characterized the gene expression signature affected by GO and dug out those genes responsible for membrane and cytoskeletal impairments upon GO. By making use of this mechanism, GO pretreatment significantly increased the cytotoxicity of chemotherapeutic agents to cancer cells. Collectively, the current study shed more light onto the interface between GO and cells and offered more insights into the molecular basis underlying GO-induced impact on cellular priming state from the perspective of changes in membrane and cytoskeleton. A 
proposed schematic depicting the findings on GO-induced sensitization of cancer cells to chemotherapeutic agents is illustrated in Figure 9. Hence, our study provides a choice for GO-based cancer nanotheranostics and may also represent a strategy to overcome the drug resistance of cancer cells and reduce the side effects of chemotherapeutic agents.

\section{METHODS AND EXPERIMENTAL SECTION}

Preparation of GO Materials. GO materials were synthesized from graphite (purchased from Qingdao BCSM. Co., Ltd. China) with the modified Hummers' method. ${ }^{64}$ Briefly, $5 \mathrm{~g}$ of graphite powder was dispersed into $120 \mathrm{~mL}$ of $\mathrm{H}_{2} \mathrm{SO}_{4}(98 \%)$ at $4{ }^{\circ} \mathrm{C}$. Thereafter, $30 \mathrm{~g}$ of $\mathrm{KMnO}_{4}$ was slowly added while stirring, and the mixture was maintained at $35{ }^{\circ} \mathrm{C}$ for $30 \mathrm{~min}$. Afterward, $230 \mathrm{~mL}$ of $\mathrm{H}_{2} \mathrm{O}$ was carefully added and maintained at $98{ }^{\circ} \mathrm{C}$. After $15 \mathrm{~min}, 500 \mathrm{~mL}$ of $\mathrm{H}_{2} \mathrm{O}$ and $10 \mathrm{~mL}$ of $\mathrm{H}_{2} \mathrm{O}_{2}(30 \%)$ were added. The mixture was filtered and washed with $1: 10 \mathrm{HCl}$ aqueous solution to remove metal ions. Next, the mixture was filtered and washed with deionized $\mathrm{H}_{2} \mathrm{O}$ until $\mathrm{pH}$ reached 7.0 and was then dried at $65{ }^{\circ} \mathrm{C}$ in a vacuum. Finally, prepared GO materials were dispersed in sterilized deionized water to prepare the stock solution $(1 \mathrm{mg} / \mathrm{mL})$ for later characterization and experiments.

Characterization of GO. $\zeta$-Potential, hydrodynamic diameter, and polydispersity index of GO materials in deionized water and culture media were assayed using a Zetasizer (Malvern Nano series, Malvern, U.K.). The FT-IR spectra of GO materials were recorded on a Nicolet 6700 FT-IR spectrophotometer (Thermo Fisher Scientific Inc., USA) using the $\mathrm{KBr}$ pellet method. TEM analysis of GO was performed on a H-7500 transmission electron microscope (Hitachi Scientific Instruments, Japan). The TEM samples were prepared by depositing a small drop of solution onto a carbon-coated copper electron microscopy grid (Beijing Zhongingkeyi Technology Co., Ltd., China) and were then dried at room temperature. With respect to XPS analysis, GO samples were deposited onto silicon wafers, air-dried, and then the silicon wafers were subjected to the assessment on a X-ray photoelectron spectroscopy. Raman spectra were recorded using an InVia Raman microscope (Renishaw, UK), equipped with 532, 633, and $785 \mathrm{~nm}$ laser lines as the excitation source. The AFM samples were prepared by depositing the dispersion on mica substrates (Beijing Zhongjingkeyi Technology Co., Ltd., China) and then dried at room temperature. AFM images were taken on an AFM 5500 instrument in the contact mode (Agilent Technologies, Inc., USA).

Cell Culture. Mouse monocyte/macrophage cell line J774A.1, human NSCLC cell line A549, human renal cancer cell line A498, and human prostate cancer cell line PC3 were obtained from the Shanghai Cell Bank of Type Culture Collection of China. Cells were cultured in DMEM (Gibco BRL Life Technologies Inc., USA) supplemented with $10 \%$ fetal bovine serum (FBS) and 100 units/mL penicillin/ streptomycin (Invitrogen) in a humidified 5\% $\mathrm{CO}_{2}$-balanced air incubator at $37{ }^{\circ} \mathrm{C}$. J774A.1 cells were semiadherent and could be readily harvested without trypsin treatment. A549, A498, and PC3 cells were adherent and were gently harvested after treatment with $0.25 \%$ trypsin solution.

Cytotoxicity Assay. For the cytotoxicity assay of GO, $2.0 \times 10^{5}$ J774A.1 or A549 cells/well were seeded in 24-well plates, respectively. Then, cells were treated with GO at various concentrations for $24 \mathrm{~h}$. After GO treatment, cells were stained with $0.4 \%$ trypan blue solution (Solarbio Science \& Technology Co., Ltd., Beijing, China), and only live cells were counted by excluding the dead cells with positive staining of trypan blue. Cellular morphology was visualized and imaged under an Axiovert 40 CFL phase-contrast microscope (Carl Zeiss, Inc., Germany). For cytotoxicity assay of DOX (Selleck Chemicals LLC, USA) and CDDP (Selleck Chemicals LLC, USA), $1.0 \times 10^{4}$ A549 cells/well were seeded in 96-well plates overnight, and cells were then treated with $\operatorname{DOX}(0.01,0.05,0.1,0.5,1,2$, and $4 \mu \mathrm{M})$ and $\operatorname{CDDP}(1,5,10,15,20,30$, and $50 \mu \mathrm{M})$ for $24 \mathrm{~h}$. Cell viability was evaluated by cell counting kit-8 (CCK8, Solarbio Science \& Technology Co., Ltd., Beijing, China) containing WST-8 (2-(2methoxy-4-nitrophenyl)-3-(4-nitrophenyl)-5-(2,4-disulfophenyl)-2H- tetrazolium). WST- 8 can be bioreduced by cellular dehydrogenases to an orange formazan product that is soluble in cell culture medium, and the amount of produced formazan is directly proportional to the number of live cells. Finally, the absorbance was measured at $450 \mathrm{~nm}$ on a Varioskan Flash Multimode plate reader (Thermo Fisher Scientific Inc., USA).

Cellular Localization of GO Sheets through TEM, Raman, and CLSM. For TEM analysis, J774A.1 and A549 cells were first treated with GO for $24 \mathrm{~h}$, followed by cell collection. Harvested cells were fixed with $2.5 \%$ glutaraldehyde solution and then embedded with epoxy resin. The ultrathin cell specimens $(70 \mathrm{~nm})$ were placed on the grids and were stained with $1 \%$ lead citrate and $0.5 \%$ uranyl acetate. Intracellular localization of GO sheets was examined using a highresolution JEOL JEM 2010F transmission electron microscope (Hitachi Scientific Instruments, Japan).

To confirm the cellular localization of GO sheets, confocal microRaman spectroscopy was performed using a Renishaw InVia Raman microscope equipped with 532, 633, and $785 \mathrm{~nm}$ laser lines as excitation sources. Briefly, the harvested cells were gently washed with phosphate buffered saline buffer (PBS buffer) and fixed with $4 \%$ paraformaldehyde solution. Raman imaging was performed with a step size of $1 \mu \mathrm{m}$ and acquisition time of $3 \mathrm{~s}$ under $10 \%$ power using a 633 nm laser.

The localization of GO was also evaluated by CLSM. Briefly, FITCBSA-labeled GO samples (Bioss Inc., China) were prepared using an established method, as described previously. ${ }^{27,65}$ FITC-BSA-labeled GO samples were washed with PBS three times to remove free FITCBSA. For confocal analysis, J774A.1 and A549 cells were seeded in 3.5 $\mathrm{cm}$ confocal dishes and FITC-BSA-labeled GO was exposed to cells. After $24 \mathrm{~h}$ exposure, cells were fixed with $4 \%$ paraformaldehyde in PBS for $10 \mathrm{~min}$ and thereafter stained with DAPI (in blue) and rhodamine-phalloidin (in red). The fluorescence of DAPI and rhodamine-phalloidin was excited at 364 and $540 \mathrm{~nm}$ and observed at 419-493 and 550-650 $\mathrm{nm}$, respectively, using a TCS SP5 laser scanning confocal microscope (Leica, Germany). FITC fluorescence was excited at $488 \mathrm{~nm}$ and measured at 500-800 nm.

Membrane Permeability Evaluation. Leakage of LDH from cells was assayed to reflect cell membrane permeability with a commercial LDH kit following the instructions provided by the manufacturer (CytoTox-ONE homogeneous membrane integrity assay, Promega, USA). Meanwhile, PI (Solarbio Science \& Technology Co., Ltd., Beijing, China) and TO-PRO-3 (Thermo Fish Scientific, USA) staining was carried out to determine membrane permeability according to the manufacturers' instructions. The fluorescence of PI and TO-PRO-3 was visualized using a TCS SP5 confocal laser scanning microscope with an excitation wavelength of 488 and $642 \mathrm{~nm}$ and an emission wavelength of 630 and $661 \mathrm{~nm}$, respectively.

Topographical Analysis of Plasma Membrane through AFM and SEM. For AFM analysis, cells were seeded in $6 \mathrm{~cm}$ plates. Thereafter, cells were exposed to GO for $24 \mathrm{~h}$, followed by the assessment on an AFM microscope (Bioscope Catalyst, Bruker, German). For SEM analysis, harvested cells were fixed with $2.5 \%$ glutaraldehyde solution following GO treatment. The topography of plasma membrane was examined by a scanning electron microscope (JSM-6400, JEOLLim. Co., Japan).

RNA-Seq Transcriptome. Total RNAs were isolated from J774A.1 cells after GO treatment at $4 \mu \mathrm{g} / \mathrm{mL}$ for 1,6 , and $24 \mathrm{~h}$. RNA-seq and data analysis were performed by the BGI Co., Ltd. (China). Fold changes at either 2 -fold greater or fewer than 0.5 -fold in GO-treated cells compared to untreated cells, a false discovery rate $(F D R) \leq 0.001$, and an absolute value of $\log _{2}$ ratio $\geq 1$ were used as the threshold to define differentially expressed genes. Gene Ontology analysis was carried out using the online GO database (http:// geneontology.org/).

Immunofluorescence Microscopy. After GO treatment, cells were washed with PBS, fixed with $4 \%$ formalin, and permeabilized with $0.5 \%$ Triton X-100. Thereafter, cells were blocked with 5\% BSA for $1 \mathrm{~h}$ at room temperature, followed by incubation of using an antibody $(\mathrm{Ab})$ against integrin $\alpha$ subunit ( $\alpha 2 \mathrm{~b}, 1: 50$, Proteintech, USA) diluted 
in 5\% BSA overnight at $4{ }^{\circ} \mathrm{C}$. After PBS washing, cells were incubated with a Cy3-conjugated secondary $\mathrm{Ab}(1: 50)$ for $1 \mathrm{~h}$ at room temperature in a moist container in the dark. The primary and secondary Abs were purchased from Proteintech (Rosemont, USA). The nuclei were stained with DAPI (Sigma-Aldrich, USA) for $10 \mathrm{~min}$ at room temperature. Afterward, cells were visualized and imaged using a TCS SP5 confocal laser scanning microscope (Olympus, Japan).

Western Blotting. After being washed with PBS, collected cells were lysed in RIPA lysis buffer (Pierce IP Lysis Buffer, USA) supplemented with protease inhibitor cocktail (Roche, Switzerland). Protein concentrations were determined with the Lowry method (Solarbio Science \& Technology Co., Ltd., Beijing, China). Equal amounts of proteins were subjected to SDS-PAGE and Western blotting. The primary Abs were as follows, anti-integrin $\alpha 2 \mathrm{~b} A \mathrm{~b}$ (1:200, Proteintech, USA), anti-FAK Ab (1:500, Proteintech, USA), anti-p-FAK $\mathrm{Ab}$ (1:1000 dilutions, CST, USA), anti-Src Ab (1:1000 dilutions, CST, USA), anti-p-Src Ab (1:1000 dilutions, CST, USA), anti-RhoA Ab (1:400, Proteintech, USA), anti-Rac1 Ab (1:1000, Proteintech, USA), anti-ROCK1 Ab (1:500, Proteintech, USA), antiROCK2 Ab (1:300, Proteintech, USA), anti-Cdc42 Ab (1:200, Proteintech, USA), and anti-GAPDH Ab (1:2000, Proteintech, USA). The second Abs were as follows: goat anti-mouse HRPconjugated IgG (1:3000, Proteintech, USA) and goat anti-rabbit HRPconjugated IgG (1:3000, Proteintech, USA). Western blotting signals were detected and developed using a BIO-RAD ChemiDoc XRS chemiluminescence system (Bio-Rad Inc., CA, USA). The intensity for autoradiogram was determined using the ImageJ software, and the band intensity was normalized to that of the loading control.

ROCK Activity Assay. After GO treatment for $24 \mathrm{~h}$, cellular ROCK activities in J774A.1 and A549 cells were measured with a ROCK activity assay kit (Millipore, USA) according to the manufacturer's instructions. Briefly, cells were collected after GO treatment and were subsequently lysed in lysis buffer (Pierce IP lysis buffer, USA) supplemented with protease inhibitor cocktail (Roche, Switzerland). Thereafter, the protein concentrations were determined with the Lowry method (Solarbio Science \& Technology Co., Ltd., Beijing, China). For ROCK activity assay, $10 \mu \mathrm{L}$ cellular lysate of each sample was tested, and the absorbance at $450 \mathrm{~nm}$ was recorded on a Varioskan Flash Multimode plate reader (Thermo Fisher Scientific Inc., USA). Finally, the ROCK activity for each sample was calculated according to the absorbance of the standard ROCK working solution provided by the manufacturer. Relative ROCK activity was normalized to the total protein concentration of each sample.

Plasmid Transfection. A549 cells were infected with lentiviral particles to express integrin $\alpha 2 \mathrm{~b}$ specific shRNAs or nontarget scrambled shRNAs (Shanghai GenePharma Co.,Ltd., China). Stable transfectants were obtained after selection with geneticin (SigmaAldrich, USA). The construct for forced expression of integrin $\alpha 2 \mathrm{~b}$ was inserted into the pLent-EF1a-FH-CMV-GP expression vector (Origene, Rockville, MD, USA). After $48 \mathrm{~h}$ plasmid transfection, cells were treated with GO at 20 and $50 \mu \mathrm{g} / \mathrm{mL}$ for $24 \mathrm{~h}$, and the total proteins were extracted for Western blotting. Plasmid transfection was performed using Lipofectamine 2000 following the manufacturer's instructions (Invitrogen). The shRNA sequences are as follows: scrambled control, GTTCTCCGAACGTGTCACGT; integrin $\alpha 2 \mathrm{~b}$ shRNA \#1, GGGATGGCTACAATGACATTG; integrin $\alpha 2 \mathrm{~b}$-shRNA \#2, GGATCTCAACACTACAGAATA.

Cell Death Analysis through FACS. For cell death analysis, A549, A498, and PC3 cells were first pretreated with GO for $24 \mathrm{~h}$ and then washed with PBS, followed by DOX or CDDP treatment for 24 h. In comparison, cells were also directly treated with GO. After treatment, cells were collected by centrifugation at $1000 \mathrm{rpm}$ and repeatedly washed with PBS three times. Afterward, $1.0 \times 10^{5}$ cells were stained with $5 \mu \mathrm{L}$ of Annexin-V FITC and $5 \mu \mathrm{L}$ of PI solutions for $15 \mathrm{~min}$ at room temperature in the dark following the manufacturer's instructions (BD Biosciences). After being stained within $1 \mathrm{~h}, 2.0 \times 10^{4}$ cells were subjected to FACS analysis using a NovoCyte D1040 flow cytometer (ACEA Biosciences Inc., China) and ACEA NovoExpress software, as previously reported. ${ }^{66,67}$
Intracellular CDDP Analysis. To determine the intracellular mass of CDDP (Pt), ICP-MS analysis was performed. Briefly, A549 cells were first pretreated with GO for $24 \mathrm{~h}$ and washed with PBS three times, followed by CDDP treatment at various concentrations for $24 \mathrm{~h}$. CDDP was purchased from Selleck Chemicals LLC with purity $>99 \%$ (Houston, TX, USA). After treatment, cells were collected after PBS washing and were afterward subjected to digestion with concentrated $\mathrm{HNO}_{3}$ (GR, 65.0\%, Millipore, USA) and $\mathrm{H}_{2} \mathrm{O}_{2}$ (GR, 30\%, Sinopharm Chemical Reagent Co., Ltd., China) at a volume ratio of $3: 1$ at $70{ }^{\circ} \mathrm{C}$ for $6 \mathrm{~h}$. Digested samples were cooled to room temperature and were diluted with deionized $\mathrm{H}_{2} \mathrm{O}$ to reach a final concentration of $2 \%$ $\mathrm{HNO}_{3}$. Finally, prepared samples were analyzed by an Agilent 7500 ICP MS instrument (Agilent, Tokyo, Japan).

Statistical Analysis. The difference of the single treated group relative to untreated control was determined using an independent $t$ test. The significance of mean difference for two or more treated groups relative to an untreated group was analyzed by a one-way ANOVA test. Data are shown in mean \pm standard deviation. $P<0.05$ was considered to be statistically significant.

\section{ASSOCIATED CONTENT}

\section{Supporting Information}

The Supporting Information is available free of charge on the ACS Publications website at DOI: 10.1021/acsnano.6b07311.

Characterization of GO materials in deionized water and cell culture medium (Figure S1); percentage of PI or TO-PRO-3 positive cells for J774A.1 or A549 after 6 and $24 \mathrm{~h}$ GO treatment (Figure S2); changes of the cellular size for J774A.1 cells after 6 and $24 \mathrm{~h}$ GO treatment (Figure S3); activation of the integrin-associated FAK/ Src complex by GO (Figure S4); cell death assay through FACS analysis with FITC-Annexin V and PI staining (Figure S5); intracellular mass of CDDP, as characterized by the intracellular concentration of $\mathrm{Pt}$ (Figure S6) (PDF)

\section{AUTHOR INFORMATION}

\section{Corresponding Authors}

*E-mail: mingxu@rcees.ac.cn.

*E-mail: sjliu@rcees.ac.cn.

ORCID

Sijin Liu: 0000-0002-5643-0734

Notes

The authors declare no competing financial interest.

\section{ACKNOWLEDGMENTS}

We thank Dr. Jian Weng for the assistance with the preparation of GO materials and Dr. Rui Liu for the assistance with the Raman imaging. This work was supported by grants under the national "973" program (Grant No. 2014CB932000) and the Strategic Priority Research Program of the Chinese Academy of Sciences (Grant No. XDB14000000), grants from the National Natural Science Foundation of China (Grant Nos. 21407169, 21425731, 21077128, and 21637004).

\section{REFERENCES}

(1) Siegel, R. L.; Miller, K. D.; Jemal, A. Cancer Statistics, 2016. CaCancer J. Clin. 2016, 66, 7-30.

(2) Torre, L. A.; Siegel, R. L.; Jemal, A. Lung Cancer Statistics. Adv. Exp. Med. Biol. 2016, 893, 1-19.

(3) Tan, W. L.; Jain, A.; Takano, A.; Newell, E. W.; Iyer, N. G.; Lim, W. T.; Tan, E. H.; Zhai, W.; Hillmer, A. M.; Tam, W. L.; et al. Novel Therapeutic Targets on the Horizon for Lung Cancer. Lancet Oncol. 2016, 17, e347-e362. 
(4) Gadgeel, S. M. Personalized Therapy of Non-small Cell Lung Cancer (NSCLC). Adv. Exp. Med. Biol. 2016, 890, 203-222.

(5) Weintraub, K. Biomedicine: The New Gold Standard. Nature 2013, 495, S14-S16.

(6) Chauhan, V. P.; Jain, R. K. Strategies for Advancing Cancer Nanomedicine. Nat. Mater. 2013, 12, 958-962.

(7) Orecchioni, M.; Cabizza, R.; Bianco, A.; Delogu, L. G. Graphene as Cancer Theranostic Tool: Progress and Future Challenges. Theranostics 2015, 5, 710-723.

(8) Yang, K.; Feng, L.; Shi, X.; Liu, Z. Nano-Graphene in Biomedicine: Theranostic Applications. Chem. Soc. Rev. 2013, 42, 530-547.

(9) Bitounis, D.; Ali-Boucetta, H.; Hong, B. H.; Min, D. H.; Kostarelos, K. Prospects and Challenges of Graphene in Biomedical Applications. Adv. Mater. 2013, 25, 2258-2268.

(10) Chung, C.; Kim, Y. K.; Shin, D.; Ryoo, S. R.; Hong, B. H.; Min, D. H. Biomedical Applications of Graphene and Graphene Oxide. Acc. Chem. Res. 2013, 46, 2211-2224.

(11) Hung, A. H.; Holbrook, R. J.; Rotz, M. W.; Glasscock, C. J.; Mansukhani, N. D.; MacRenaris, K. W.; Manus, L. M.; Duch, M. C.; Dam, K. T.; Hersam, M. C.; et al. Graphene Oxide Enhances Cellular Delivery of Hydrophilic Small Molecules by Co-incubation. ACS Nano 2014, 8, 10168-10177.

(12) Chen, G. Y.; Meng, C. L.; Lin, K. C.; Tuan, H. Y.; Yang, H. J.; Chen, C. L.; Li, K. C.; Chiang, C. S.; Hu, Y. C. Graphene Oxide as A Chemosensitizer: Diverted Autophagic Flux, Enhanced Nuclear Import, Elevated Necrosis and Improved Antitumor Effects. Biomaterials 2015, 40, 12-22.

(13) Li, J.; Lyv, Z.; Li, Y.; Liu, H.; Wang, J.; Zhan, W.; Chen, H.; Chen, H.; Li, X. A Theranostic Prodrug Delivery System Based on $\mathrm{Pt}(\mathrm{IV})$ Conjugated Nano-graphene Oxide with Synergistic Effect to Enhance the Therapeutic Efficacy of Pt Drug. Biomaterials 2015, 51, $12-21$.

(14) Chen, Y.; Wu, Y.; Sun, B.; Liu, S.; Liu, H. Two-Dimensional Nanomaterials for Cancer Nanotheranostics. Small 2017, 1603446.

(15) Gupta, S. C.; Kannappan, R.; Reuter, S.; Kim, J. H.; Aggarwal, B. B. Chemosensitization of Tumors by Resveratrol. Ann. N. Y. Acad. Sci. 2011, 1215, 150-160.

(16) Monisha, J.; Padmavathi, G.; Roy, N. K.; Deka, A.; Bordoloi, D.; Anip, A.; Kunnumakkara, A. B. NF- $\kappa$ B Blockers Gifted by Mother Nature: Prospectives in Cancer Cell Chemosensitization. Curr. Pharm. Des. 2016, 22, 4173-4200.

(17) Chang, T. Y.; Chen, H. A.; Chiu, C. F.; Chang, Y. W.; Kuo, T. C.; Tseng, P. C.; Wang, W.; Hung, M. C.; Su, J. L. Dicer Elicits Paclitaxel Chemosensitization and Suppresses Cancer Stemness in Breast Cancer by Repressing AXL. Cancer Res. 2016, 76, 3916-3928.

(18) Gandhi, N. S.; Tekade, R. K.; Chougule, M. B. Nanocarrier Mediated Delivery of siRNA/miRNA in Combination with Chemotherapeutic Agents for Cancer Therapy: Current Progress and Advances. J. Controlled Release 2014, 194, 238-256.

(19) Rahman, M.; Akhter, S.; Ahmad, M. Z.; Ahmad, J.; Addo, R. T.; Ahmad, F. J.; Pichon, C. Emerging Advances in Cancer Nanotheranostics with Graphene Nanocomposites: Opportunities and Challenges. Nanomedicine 2015, 10, 2405-2422.

(20) Chen, Y.; Xu, M.; Zhang, J.; Ma, J.; Gao, M.; Zhang, Z.; Xu, Y.; Liu, S. Genome-wide DNA Methylation Variations upon Engineered Nanomaterials and Their Implications in Nanosafety Assessment. $A d v$. Mater. 2017, 29, 1604580.

(21) Meldrum, D. R.; Cleveland, J. C., Jr.; Moore, E. E.; Partrick, D. A.; Banerjee, A.; Harken, A. H. Adaptive and Maladaptive Mechanisms of Cellular Priming. Ann. Surg. 1997, 226, 587-598.

(22) Conrath, U.; Beckers, G. J.; Flors, V.; García-Agustín, P.; Jakab, G.; Mauch, F.; Newman, M. A.; Pieterse, C. M.; Poinssot, B.; Pozo, M. J.; et al. Priming: Getting Ready for Battle. Mol. Plant-Microbe Interact. 2006, 19, 1062-1071.

(23) Qu, G.; Wang, X.; Wang, Z.; Liu, S.; Jiang, G. B. Cytotoxicity of Quantum Dots and Graphene Oxide to Erythroid Cells and Macrophages. Nanoscale Res. Lett. 2013, 8, 198.
(24) Qu, G.; Wang, X.; Liu, Q.; Liu, R.; Yin, N.; Ma, J.; Chen, L.; He, J.; Liu, S.; Jiang, G. B. The Ex Vivo and In Vivo Biological Performances of Graphene Oxide and the Impact of Surfactant on Graphene Oxide's Biocompatibility. J. Environ. Sci. 2013, 25, 873-881.

(25) Qu, G.; Liu, S.; Zhang, S.; Wang, L.; Wang, X.; Sun, B.; Yin, N.; Gao, X.; Xia, T.; Chen, J. J.; et al. Graphene Oxide Induces Toll-like Receptor 4 (TLR4)-Dependent Necrosis in Macrophages. ACS Nano 2013, 7, 5732-5745.

(26) Ma, J.; Liu, R.; Wang, X.; Liu, Q.; Chen, Y.; Valle, R. P.; Zuo, Y. Y.; Xia, T.; Liu, S. Crucial Role of Lateral Size for Graphene Oxide in Activating Macrophages and Stimulating Pro-inflammatory Responses in Cells and Animals. ACS Nano 2015, 9, 10498-10515.

(27) Xu, M.; Zhu, J.; Wang, F.; Xiong, Y.; Wu, Y.; Wang, Q.; Weng, J.; Zhang, Z.; Chen, W.; Liu, S. Improved In Vitro and In Vivo Biocompatibility of Graphene Oxide through Surface Modification: Poly(Acrylic Acid)-Functionalization is Superior to PEGylation. ACS Nano 2016, 10, 3267-3281.

(28) Zou, X.; Zhang, L.; Wang, Z.; Luo, Y. Mechanisms of the Antimicrobial Activities of Graphene Materials. J. Am. Chem. Soc. 2016, 138, 2064-2077.

(29) Geng, Y.; Wang, S. J.; Kim, J. K. Preparation of Graphite Nanoplatelets and Graphene Sheets. J. Colloid Interface Sci. 2009, 336, 592-598.

(30) Patil, A. J.; Vickery, J. L.; Scott, T. B.; Mann, S. Aqueous Stabilization and Self-Assembly of Graphene Sheets into Layered BioNanocomposites using DNA. Adv. Mater. 2009, 21, 3159-3164.

(31) Liu, J.; Fu, S.; Yuan, B.; Li, Y.; Deng, Z. Toward A Universal "Adhesive Nanosheet" for the Assembly of Multiple Nanoparticles Based On A Protein-induced Reduction/Decoration of Graphene Oxide. J. Am. Chem. Soc. 2010, 132, 7279-7281.

(32) Yamada, K. M.; Miyamoto, S. Integrin Transmembrane Signaling and Cytoskeletal Control. Curr. Opin. Cell Biol. 1995, 7, 681-689.

(33) Calderwood, D. A.; Shattil, S. J.; Ginsberg, M. H. Integrins and Actin Filaments: Reciprocal Regulation of Cell Adhesion and Signaling. J. Biol. Chem. 2000, 275, 22607-22610.

(34) Humphries, J. D.; Byron, A.; Humphries, M. J. Integrin Ligands at A Glance. J. Cell Sci. 2006, 119, 3901-3903.

(35) Winograd-Katz, S. E.; Fässler, R.; Geiger, B.; Legate, K. R. The Integrin Adhesome: from Genes and Proteins to Human Disease. Nat. Rev. Mol. Cell Biol. 2014, 15, 273-288.

(36) Desgrosellier, J. S.; Cheresh, D. A. Integrins in Cancer: Biological Implications and Therapeutic Opportunities. Nat. Rev. Cancer 2010, 10, 9-22.

(37) Paolillo, M.; Russo, M. A.; Serra, M.; Colombo, L.; Schinelli, S. Small Molecule Integrin Antagonists in Cancer Therapy. Mini-Rev. Med. Chem. 2009, 9, 1439-1446.

(38) Mitra, S. K.; Schlaepfer, D. D. Integrin-regulated FAK-Src Signaling in Normal and Cancer Cells. Curr. Opin. Cell Biol. 2006, 18, $516-523$.

(39) Gupton, S. L.; Gertler, F. B. Integrin Signaling Switches the Cytoskeletal and Exocytic Machinery that Drives Neuritogenesis. Dev. Cell 2010, 18, 725-736.

(40) Lee, S. H.; Dominguez, R. Regulation of Actin Cytoskeleton Dynamics in Cells. Mol. Cells 2010, 29, 311-325.

(41) Spiering, D.; Hodgson, L. Dynamics of the Rho-family Small GTPases in Actin Regulation and Motility. Cell Adhes. Migr. 2011, 5, 170-180.

(42) Smith, H. W.; Marshall, C. J. Regulation of Cell Signalling by uPAR. Nat. Rev. Mol. Cell Biol. 2010, 11, 23-36.

(43) Schmandke, A.; Schmandke, A.; Strittmatter, S. M. ROCK and Rho: Biochemistry and Neuronal Functions of Rho-Associated Protein Kinases. Neuroscientist 2007, 13, 454-469.

(44) Jin, H.; Varner, J. Integrins: Roles in Cancer Development and as Treatment Targets. Br. J. Cancer 2004, 90, 561-565.

(45) Desgrosellier, J. S.; Cheresh, D. A. Integrins in Cancer: Biological Implications and Therapeutic Opportunities. Nat. Rev. Cancer 2010, 10, 9-22. 
(46) Danhier, F.; Le Breton, A.; Préat, V. RGD-based Strategies to Target Alpha(v) Beta(3) Integrin in Cancer Therapy and Diagnosis. Mol. Pharmaceutics 2012, 9, 2961-2973.

(47) Chen, I. H.; Shih, H. C.; Hsieh, P. W.; Chang, F. R.; Wu, Y. C.; Wu, C. C. HPW-RX40 Restores Anoikis Sensitivity of Human Breast Cancer Cells by Inhibiting Integrin/FAK Signaling. Toxicol. Appl. Pharmacol. 2015, 289, 330-340.

(48) Lin, L.; Yan, F.; Zhao, D.; Lv, M.; Liang, X.; Dai, H.; Qin, X.; Zhang, Y.; Hao, J.; Sun, X.; et al. Reelin Promotes the Adhesion and Drug Resistance of Multiple Myeloma Cells via Integrin $\beta 1$ Signaling and STAT3. Oncotarget 2016, 7, 9844-9858.

(49) Schwartz, M. A.; McRoberts, K.; Coyner, M.; Andarawewa, K. L.; Frierson, H. F., Jr.; Sanders, J. M.; Swenson, S.; Markland, F.; Conaway, M. R.; Theodorescu, D. Integrin Agonists as Adjuvants in Chemotherapy for Melanoma. Clin. Cancer Res. 2008, 14, 6193-6197.

(50) Hsieh, Y. T.; Gang, E. J.; Geng, H.; Park, E.; Huantes, S.; Chudziak, D.; Dauber, K.; Schaefer, P.; Scharman, C.; Shimada, H.; et al. Integrin Alpha4 Blockade Sensitizes Drug Resistant Pre-B Acute Lymphoblastic Leukemia to Chemotherapy. Blood 2013, 121, 18141818.

(51) Nelson, E. S.; Folkmann, A. W.; Henry, M. D.; DeMali, K. A. Vinculin Activators Target Integrins from within the Cell to Increase Melanoma Sensitivity to Chemotherapy. Mol. Cancer Res. 2011, 9, $712-723$.

(52) McLean, G. W.; Carragher, N. O.; Avizienyte, E.; Evans, J.; Brunton, V. G.; Frame, M. C. The Role of Focal-adhesion Kinase in Cancer - A New Therapeutic Opportunity. Nat. Rev. Cancer 2005, 5, 505-515.

(53) Rath, N.; Olson, M. F. Rho-associated Kinases in Tumorigenesis: Re-considering ROCK Inhibition for Cancer Therapy. EMBO Rep. 2012, 13, 900-908.

(54) Liu, S. The ROCK Signaling and Breast Cancer Metastasis. Mol. Biol. Rep. 2011, 38, 1363-1366.

(55) Qu, G.; Zhang, C.; Yuan, L.; He, J.; Wang, Z.; Wang, L.; Liu, S.; Jiang, G. Quantum Dots Impair Macrophagic Morphology and the Ability of Phagocytosis by Inhibiting the Rho-associated Kinase Signaling. Nanoscale 2012, 4, 2239-2244.

(56) Chen, L.; Qu, G.; Zhang, C.; Zhang, S.; He, J.; Sang, N.; Liu, S. Quantum Dots (QDs) Restrain Human Cervical Carcinoma HeLa Cell Proliferation through Inhibition of the ROCK-c-Myc Signaling. Integr. Biol.-UK 2013, 5, 590-596.

(57) Otterson, G. A.; Villalona-Calero, M. A.; Hicks, W.; Pan, X.; Ellerton, J. A.; Gettinger, S. N.; Murren, J. R. Phase I/II Study of Inhaled Doxorubicin Combined with Platinum-based Therapy for Advanced Non-small Cell Lung Cancer. Clin. Cancer Res. 2010, 16, 2466-2473.

(58) Dasari, S.; Tchounwou, P. B. Cisplatin in Cancer Therapy: Molecular Mechanisms of Action. Eur. J. Pharmacol. 2014, 740, 364378.

(59) Akhavan, O.; Ghaderi, E. Toxicity of Graphene and Graphene Oxide Nanowalls Against Bacteria. ACS Nano 2010, 4, 5731-5736.

(60) Tu, Y.; Lv, M.; Xiu, P.; Huynh, T.; Zhang, M.; Castelli, M.; Liu, Z.; Huang, Q.; Fan, C.; Fang, H.; et al. Destructive Extraction of Phospholipids from Escherichia coli Membranes by Graphene Nanosheets. Nat. Nanotechnol. 2013, 8, 594-601.

(61) Li, Y.; Yuan, H.; von dem Bussche, A.; Creighton, M.; Hurt, R. H.; Kane, A. B.; Gao, H. Graphene Microsheets Enter Cells through Spontaneous Membrane Penetration at Edge Asperities and Corner Sites. Proc. Natl. Acad. Sci. U. S. A. 2013, 110, 12295-12300.

(62) Roa, W.; Zhang, X.; Guo, L.; Shaw, A.; Hu, X.; Xiong, Y.; Gulavita, S.; Patel, S.; Sun, X.; Chen, J.; et al. Gold Nanoparticle Sensitize Radiotherapy of Prostate Cancer Cells by Regulation of the Cell Cycle. Nanotechnology 2009, 20, 375101.

(63) Liu, J.; Ma, X.; Jin, S.; Xue, X.; Zhang, C.; Wei, T.; Guo, W.; Liang, X. J. Zinc Oxide Nanoparticles as Adjuvant To Facilitate Doxorubicin Intracellular Accumulation and Visualize $\mathrm{pH}$-Responsive Release for Overcoming Drug Resistance. Mol. Pharmaceutics 2016, 13, $1723-1730$.
(64) Kovtyukhova, N. I.; Ollivier, P. J.; Martin, B. R.; Mallouk, T. E.; Chizhik, S. A.; Buzaneva, E. V.; Gorchinskiy, A. D. Layer-by-Layer Assembly of Ultrathin Composite Films from Micron-Sized Graphite Oxide Sheets and Polycations. Chem. Mater. 1999, 11, 771-778.

(65) Mu, Q. X.; Su, G. M.; Li, L. W.; Gilbertson, B. O.; Yu, L. H.; Zhang, Q.; Sun, Y. P.; Yan, B. Size-Dependent Cell Uptake of ProteinCoated Graphene Oxide Nanosheets. ACS Appl. Mater. Interfaces 2012, 4, 2259-2266.

(66) Chen, Y.; Wang, Z.; Xu, M.; Wang, X.; Liu, R.; Liu, Q.; Zhang, Z.; Xia, T.; Zhao, J.; Jiang, G.; et al. Nanosilver Incurs An Adaptive Shunt of Energy Metabolism Mode to Glycolysis in Tumor and Nontumor cells. ACS Nano 2014, 8, 5813-5825.

(67) Gao, M.; Liu, Y.; Chen, Y.; Yin, C.; Chen, J.-J.; Liu, S. MiR-214 Protects Erythroid Cells Against Oxidative Stress by Targeting ATF4 and EZH2. Free Radical Biol. Med. 2016, 92, 39-49. 